Article

\title{
Collaborative Networks: A Pillar of Digital Transformation
}

\author{
Luis M. Camarinha-Matos ${ }^{1, * \mathbb{C}}$, Rosanna Fornasiero ${ }^{2}$, Javaneh Ramezani ${ }^{1}{ }^{\mathbb{C}}$ and Filipa Ferrada ${ }^{1}$ \\ 1 Faculty of Sciences and Technology and Uninova CTS, NOVA University of Lisbon, Campus de Caparica, \\ 2829-516 Caparica, Portugal; ramezanijavaneh@gmail.com (J.R.); faf@uninova.pt (F.F.) \\ 2 Institute of Intelligent Industrial Technologies and Systems for Advanced Manufacturing, \\ National Research Council, Via Corti, 12, 20133 Milan, Italy; Rosanna.Fornasiero@stiima.cnr.it \\ * Correspondence: cam@uninova.pt
}

Received: 5 November 2019; Accepted: 8 December 2019; Published: 11 December 2019

\begin{abstract}
The notion of digital transformation encompasses the adoption and integration of a variety of new information and communication technologies for the development of more efficient, flexible, agile, and sustainable solutions for industrial systems. Besides technology, this process also involves new organizational forms and leads to new business models. As such, this work addresses the contribution of collaborative networks to such a transformation. An analysis of the collaborative aspects required in the various dimensions of the 4 th industrial revolution is conducted based on a literature survey and experiences gained from several research projects. A mapping between the identified collaboration needs and research results that can be adopted from the collaborative networks area is presented. Furthermore, several new research challenges are identified and briefly characterized.
\end{abstract}

Keywords: collaborative networks; digital transformation; Industry 4.0; smart manufacturing

\section{Introduction}

The widely disseminated idea that we are at the beginning of a "4th industrial revolution" has attracted considerable attention both from business and academia. This movement, often named as "Industry 4.0" or "Smart Manufacturing", became more visible after a program launched by the German government and the development of similar initiatives in USA and other countries [1,2]. It was also encouraged by programs such as the "Factories of the Future" from the European Union [3]. The initial notion was primarily focusing the convergence of physical and virtual worlds, as represented by the term "cyber-physical system (CPS)", thus promoting a "CPS-based industry". Along these lines, even the term CPPS (cyber-physical production system) emerged [4,5]. Soon this idea gradually developed into a combination of CPS, "Internet of Things (IoT)", and "Internet of Services (IoS)", showing an evolution towards digitalization or digital transformation. The initial perspective was further complemented with the facet of "smartness" or "intelligence" as shown by the terms "smart machines", "smart sensors", "smart factory", "smart environments", "smart products", etc. [6]. This industrial revolution, therefore, results from a close combination of contributions from different sub-fields of engineering, computer science, and more specifically artificial intelligence, and manufacturing.

This trend induces several benefits, such as the "creation of a momentum" to drive a significant industrial transformation, upgrading, and even revitalization. This comes from leveraging the synergies of multi-disciplinary contributions, promoting wide multi-stakeholder discussions on new industry directions, sharing of experiences, and identification of new opportunities, as evidenced by the large number of academic and business-oriented publications on Industry 4.0. The wide interest for the area also created "opportunities for attracting new political and financial support" [7]. This is clearly 
shown by the fact that many countries have launched specific development programs on Industry 4.0 and digital transformation. The same ideas are being adopted in many other sectors, becoming a kind of "4.0 fever", as illustrated by terms such as "Economy 4.0", "Agriculture 4.0", "Health 4.0", "Water 4.0 ", "Education 4.0", “Tourism 4.0", etc.

To some extent, the term "Industry $4.0^{\prime \prime}$ became a buzzword [8], but also a trigger for the "convergence and integration" of a variety of new technologies and the deployment of new or revised manufacturing-related concepts, creating a kind of "me too effect". As a result of the growing attention, the scope of Industry 4.0 progressively increased, as if "everything fits", which makes the concept somehow elusive, often leading to misunderstandings and a proliferation of partial views. Despite the aforementioned benefits, there is also some risk associated with this transformation process. The hype created leads to an excess of expectations, and even to some of the hard challenges being overlooked. Furthermore, often newcomers tend to look at Industry 4.0 from the narrow perspective, limited by their field of interest, which may lead to some deviation from the original vision and aims. A warning signal is that some publications and talks in technical and business events sound like the 1980s discussions around the old "computer-integrated manufacturing (CIM)" concept, but now face-lifted with the use of some new technologies.

In this article we argue that to adequately grasp the holistic vision brought in by Industry 4.0 and the associated digital transformation, it is beneficial to examine it through the lens of collaborative networks (CNs). Certainly, one may say that this is "yet another partial view". Nevertheless, on the one hand a collaboration perspective is present, either explicitly or implicitly, in most requirements of Industry 4.0; on the other hand, CNs embed an interdisciplinary and multi-disciplinary nature, which can be helpful for getting a holistic understanding of the problems involved in this transformation. Therefore, we claim that "collaboration" is a crucial challenge for the 4th industrial revolution, and thus the "Collaborative Networks" area, among others, needs to be taken as a core enabler for this transformation. In support of this claim we can notice some relevant keywords associated to Industry 4.0 including "networking", "vertical and horizontal integration", "value chains", and "co-engineering/through engineering", that fit well the topics in the research agenda of the $\mathrm{CN}$ community [1,9]. A relatively recent literature survey [10] further points out that "interconnection" and "collaboration" are among the main detected "clusters of terms". Considering this context, this work is guided by two main questions:

- In which ways can collaborative networks contribute to Industry 4.0 and associated digital transformation? and

- Which further research challenges are induced by the vision of Industry 4.0 and digital transformation aimed at?

As such, we performed an analysis of requirements of Industry 4.0, namely in terms of its main dimensions and focused on identifying the involved collaboration-related issues, while also mapping them to results that can be adopted from the $\mathrm{CN}$ area. Additionally, we suggest a list of "open issues" for further research and development towards a new "Collaborative Industry 4.0". In other words, our point is that the areas of Industry 4.0 and collaborative networks can mutually benefit from a co-evolution process.

The remainder of this article is structured as follows: in Section 2 the adopted research method and used inputs are briefly described; Sections 3 and 4 briefly characterize the areas of Industry 4.0 and collaborative networks, providing a background for the following sections; Section 5 analyses the main

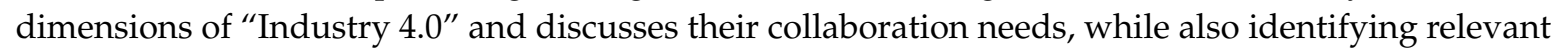
results that can be "borrowed" from the $\mathrm{CN}$ area; Section 6 complements this analysis by looking at the issues of coping with disruptive events, a crucial issue that crosses all dimensions, and the potential role of CNs; Section 7 introduces and discusses further research challenges; finally Section 8 presents some conclusions. 


\section{Materials and Methods}

A mixed method, combining a systematic mapping study based on literature [11] with case studies from various research projects and some form of participatory research, was adopted in this work.

For the literature survey part, this mapping is reflected in the effort to synthetize the main features of the two areas, namely Industry 4.0 and digital transformation in Section 3 and collaborative networks in Section 4, and the points of cross fertilization between the two areas as in Sections 5 and 6. For the case studies part, experiences acquired in a number of research projects, e.g., ECOLEAD, GloNet, ARCON-ACM, Next-Net, DigiFof, and vf-OS, were considered.

Complementarily, through active leading role in a series of recent conferences (PRO-VE: Working Conference on Virtual Enterprises and DoCEIS: Advanced Doctoral Conference on Computing, Electrical and Industrial Systems), the authors organized various focused discussions on the trends in smart and sustainable manufacturing, and next generation of $\mathrm{CNs}$, and collected feedback to refine and consolidate the findings presented in this article. As a starting point, a position paper [7] was discussed, followed by discussions in focus groups on the topics of Digital Transformation and CNs along the last three years.

Finally, the work is also guided by the general principles of research roadmapping [12,13], namely in terms of (i) analysis of baseline, (ii) definition of a strategic vision, (iii) research gap analysis, and (iv) proposal for a research agenda. Results of (i) and (ii) are reflected in Sections 3-6 and results of steps (iii) and (iv) are included in Section 7.

\section{Industry 4.0 and Digital Transformation}

Two main characteristics of the ongoing "industrial revolution" are digitalization and intense interconnection of components, systems, value chains, products, and processes, which trigger the development of new business models. The transformation towards the extensive adoption of digital technologies to create/modify business services, processes, culture, and customer involvement/experiences to meet fast-changing business and market requirements is known as "digital transformation". Of special relevance in this process is the interconnection of the cyber and physical worlds via "Cyber-Physical Systems" and "Internet of Things". One of the relevant notions in this regard is the "representation" of physical entities in the cyber world, which led to the concept of "digital twin". According to [14,15], a "digital twin" is a real-time "reflection" of a physical device or sub-system in the cyberspace, being permanently synchronized with the real-world asset. Furthermore, the concept is evolving to assume a complete integration with the physical component, allowing access to both real-time data flows and historical data. When combined with simulation mechanisms and artificial intelligence, it can support verification and analysis of measured and predicted behaviors.

In the literature, Industry 4.0 is often discussed in reference to 4 main dimensions, i.e., [7]: (1) "vertical integration/networking", (2) "horizontal integration/networking", (3) "through-engineering", and (4) "acceleration of manufacturing" $[1,16]$. Some publications also refer two additional dimensions: (5) “digitalization of products and services", and (6) "new business models and customer involvement" [17]. These dimensions can be described briefly as:

(1) "Vertical integration" relates to integrating systems and processes vertically across the whole organization, i.e., networking all its units, from the shop floor layer (e.g., "smart production systems", "smart products", "smart logistics"), up to the engineering and business layers (e.g., engineering and development, product and production management, quality assurance, marketing, etc.) $[1,10,16]$. This interconnection through information and communication technology (ICT) [18] is expected to allow easy data access and transparency, facilitating decision-making and agility. As sub-systems progressively become smarter, more than integration the direction is towards seeing the organization as a network of smart (and partially autonomous) units. 
(2) "Horizontal integration" refers to "networking along the whole value chain, from suppliers and business partners to customers" $[1,10,19]$, bringing them into a "close working relationship with each other", i.e., "in order to achieve seamless and secure cooperation between enterprises" and towards the market [9,20-22]. Horizontal integration should be based on a reliable and secure infrastructure supporting the collaboration between manufacturing organizations and their partners in the supply chain. Through such support all actors and units involved can communicate changes and share information in real-time. This infrastructure also allows collaboration with technology and machine providers, and software developers, by offering them a standardized framework for interaction [23,24].

(3) "Through-engineering" dimension, also known as "end-to-end engineering", integrates all engineering-related activities involved in the entire product lifecycle, from design/manufacturing to disposal/recycling $[1,16]$. Digitalization enables new functions for collaboration at the various phases of the lifecycle where different actors are involved, supported by the exchange of large volumes of data on products and processes. It also allows better interaction with the customer. New meanings to "design" can be given, going far beyond the product per se but linking the product to specific needs of the market, e.g., design for environment, design for maintenance, customized product configuration.

(4) "Acceleration of manufacturing" focuses on optimizing the entire value chain, resorting to the integration of the "exponential technologies" (i.e., technologies that have an exponential growth), and "accelerating and making industrial processes more flexible" [1,16]. In fact, some of these technologies have been around for many years, e.g., robotics, artificial intelligence (AI), neuro-technologies, but a significant development boost only recently became evident. Often more than one of these technologies enter the manufacturing arena simultaneously, which in some cases leads to disruptive transformations. These combined effects also lead to the notion of "acceleration of manufacturing".

(5) "Digitalization of products and services" not only relates to creating digital models of products but also to moving toward "smart products", through the addition of sensing, computing, and communication capabilities to these products. This also comprises (1) availability of product data along the product's lifecycle (facilitating tracking and tracing), (2) introduction of new "digital products", and (3) adding "business services" to the physical products $[17,25]$. The idea of "service-enhanced products" or "product-service-systems" is now well-known in the market, where even several products are living a new commercial life thanks to integrated and embedded services. In some sectors, the value offered to the customer is not any more focused on the physical product but rather on the associated business services that provide value to the customer (servitization trend) $[25,26]$.

(6) “New business models and customer involvement", focusing on innovative business models that take advantage of the digitalization process, networking along the value chain, and data-rich contexts. These models explore new possibilities offered by technology and foster closer "digital relationships" with more demanding and empowered customers. Furthermore, they "accelerate globalization but with distinct local/regional flavors" [7,17]. For instance, the platform-based economy [27], big data-driven value chain [28], sharing economy, software as a service, etc., are some of the models under discussion both at scientific and industrial level to fully exploit the potential of digitalization. 
Two main "forces" drive the industrial transformation towards Industry 4.0, namely the fast-changing market demands, and the new technological possibilities, as illustrated in Figure 1.

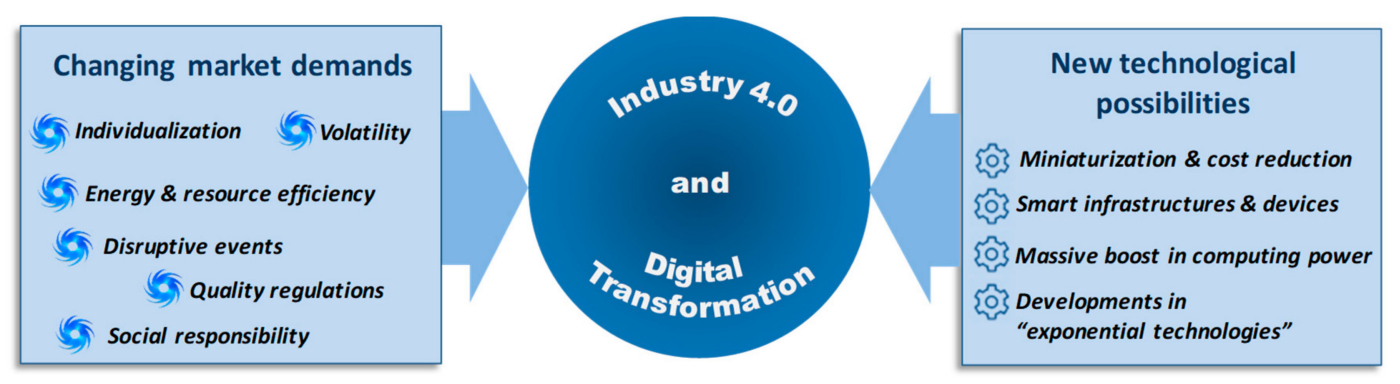

Figure 1. Transformation driving forces.

In terms of market and society, factors such as individualization/high customization, market volatility, sustainability concerns and social responsibility, coping with regulatory requirements and disruptive events, force industries to seek higher levels of agility, new forms of operation, and holistic views of optimization. From the technological side, the transformation is in fact induced by the integration of several new technologies [29-31]. Another core issue is the role played by data, which become available in fast-growing volumes. Besides the need to re-design legacy systems and mechanisms, this also leads to the emergence of new services and products.

A synthetic overview of the main issues/challenges in each dimension and main supporting technologies can be found in Table 1. This table includes a list of relevant examples, which is not exhaustive but rather illustrative.

Table 1. Examples of characteristics and technologies in Industry 4.0.

\begin{tabular}{|c|c|c|c|}
\hline & Dimension & Some Relevant Topics/Key Challenges & Examples of Core Enabling Technologies \\
\hline 1 & $\begin{array}{l}\text { Vertical integration of smart } \\
\text { production systems }\end{array}$ & $\begin{array}{ll}\text { - } & \text { Interoperability } \\
\text { - } & \text { Decentralization and Modularization } \\
\text { - } & \text { Service orientation } \\
\text { - } & \text { Needs-oriented and individualized } \\
\text { - } & \text { Fast decision-making processes } \\
\text { - } & \text { Agility and reconfigurability } \\
\text { - } & \text { Sustainability } \\
\text { - } & \text { Optimization models }\end{array}$ & $\begin{array}{l}\text { - Extensive cyber physical systems } \\
\text { (CPS) and Internet of Things (IoT) } \\
\text { - Sensing and real-time availability } \\
\text { of data } \\
\text { - Artificial intelligence } \\
\text { - Virtualization of processes, } \\
\text { digital twins } \\
\text { - Data analytics } \\
\text { - Augmented reality } \\
\text { - Cybersecurity and Distributed ledger }\end{array}$ \\
\hline 2 & $\begin{array}{l}\text { Horizontal integration through } \\
\text { global value chain networks }\end{array}$ & $\begin{array}{ll}\text { - } & \text { Collaboration and Transparency } \\
\text { - } & \text { Interoperability } \\
\text { - } & \text { Decentralization } \\
\text { - } & \text { Business ecosystems } \\
\text { - } & \text { Global optimization and flexibility } \\
\text { - } & \text { Resilience } \\
\text { - } & \text { Regulatory framework } \\
\text { - } & \text { Data sharing, tracking and tracing }\end{array}$ & $\begin{array}{ll}\text { - } & \text { Cloud computing } \\
\text { - } & \text { Collaboration platforms } \\
\text { - } & \text { Mobile computing and IoT } \\
\text { - } & \text { Safety and security } \\
\text { - } & \text { Distributed business } \\
\text { - } & \text { Processes orchestration } \\
\text { - } & \text { ybersecurity and Distributed ledger }\end{array}$ \\
\hline 3 & $\begin{array}{l}\text { Through-engineering across the } \\
\text { entire value chain }\end{array}$ & $\begin{array}{l}\text { - Co-engineering, co-design } \\
\text { - } \text { "End-to-end integration" } \\
\text { - Circular economy } \\
\text { - Connection of and } \\
\text { customers involvement } \\
\text { - Tracking and tracing } \\
\text { - Data privacy on personal data } \\
\text { - Intellectual property management }\end{array}$ & 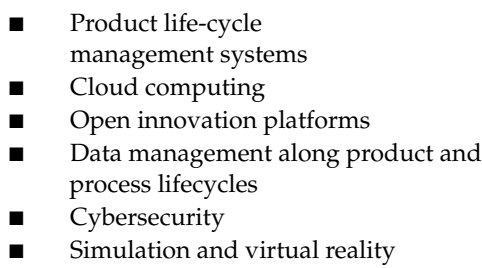 \\
\hline
\end{tabular}


Table 1. Cont.

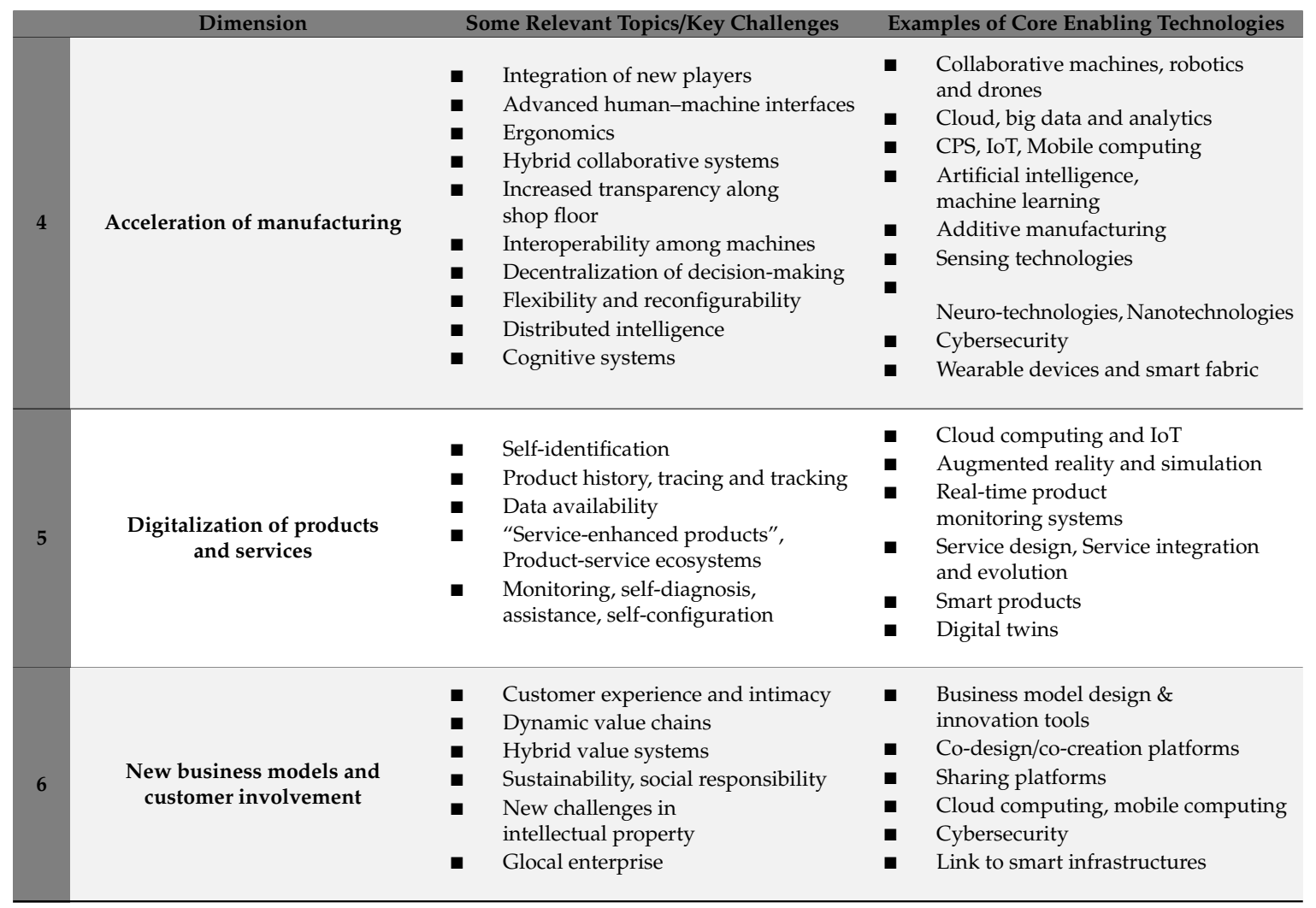

\section{Collaborative Networks}

Nowadays, CNs are being applied to a great variety of domains, moving from academic research to manufacturing and other industrial applications [32-34]. These implementations are supported by a variety of collaboration forms, which range from "supply chains" to emerging dynamic structures in industry, science, and services. The multiple CN manifestations can be organized in a taxonomy, which has been evolving with the advances of ICT tools in the last two or three decades. Figure 2 shows a partial CN taxonomy, based on $[35,36]$.

The first level of the $\mathrm{CN}$ taxonomy distinguishes between "collaborative networked organization (CNO)" and "ad-hoc collaboration". A CNO characterizes a network, typically business-oriented, with solid organizational aspects in terms of structure, roles definition, and governance rules, while an ad hoc collaboration characterizes a spontaneous and not structured network which might emerge for instance, in a crisis. There are two main classes of CNOs: (i) the goal-oriented networks and (ii) the long-term strategic networks.

Goal-oriented networks are networks characterized by intense interaction among its participants aiming at reaching a common goal. They include the (a) continuous production-driven networks, which are networks that remain stable for a long period of time with well-defined roles for their participants. Supply chains or collaborative smart grids are examples of such networks; and the (b) grasping opportunity-driven networks, i.e., networks that are dynamically created to pursue some business opportunity within a limited time window. Virtual organizations (VO)/virtual enterprises (VE) and virtual teams (VT) are examples of such networks, which are composed of groups of independent organizations or individuals sharing skills and resources in response to business opportunities [35]. 


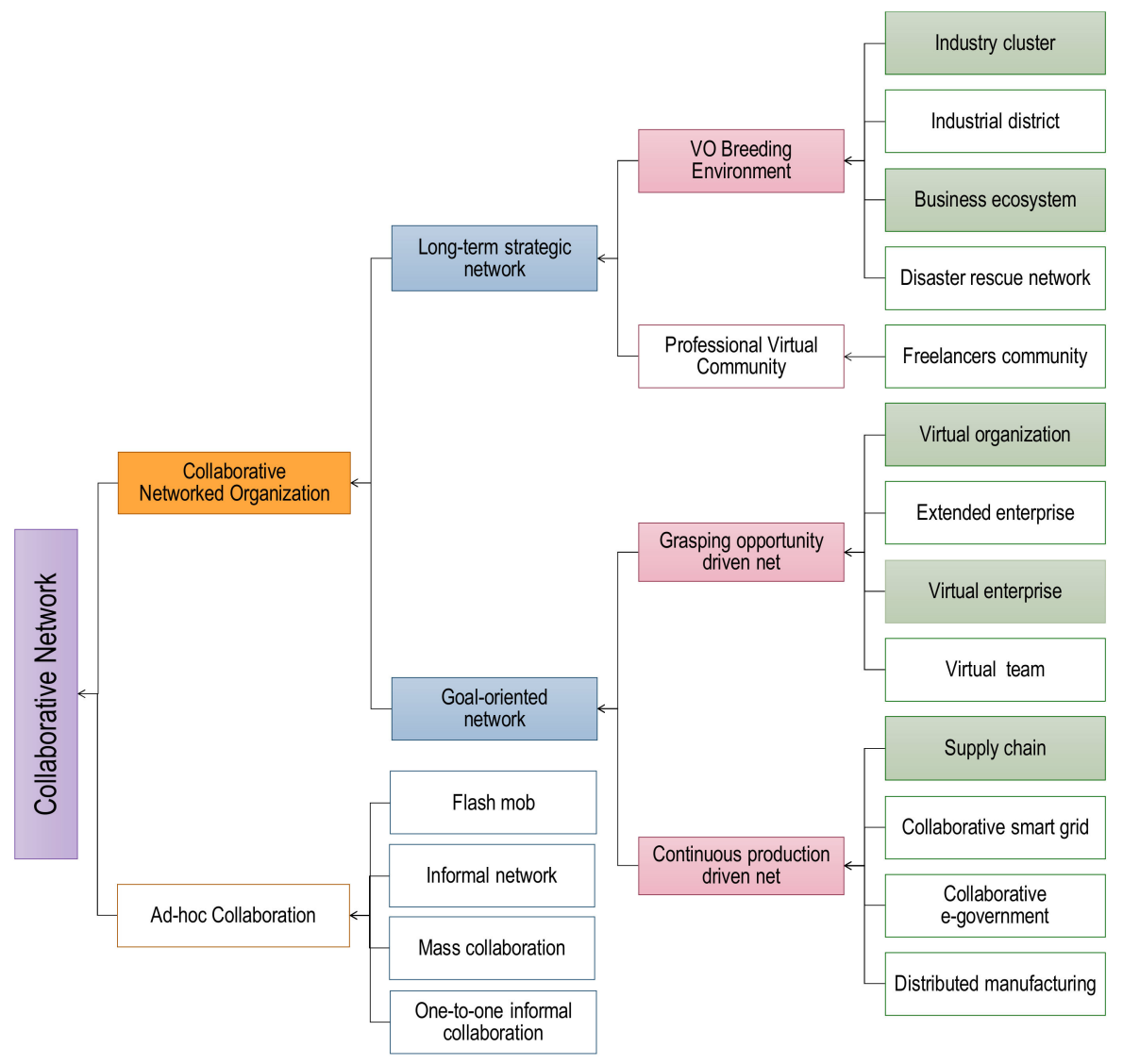

Figure 2. A partial taxonomy of collaborative networks (CNs).

In turn, long-term strategic networks are characterized as strategic alliances created to act as source or breeding environments for "goal-oriented networks", i.e., aimed at providing proper conditions and support environment for dynamic creation of goal-oriented networks whenever a business opportunity arises. This class includes the (a) professional virtual communities (PVC), which are networks composed of individual professionals that get together in a long term basis to be prepared to rapidly react in response to business opportunities through the dynamic creation of temporary VTs, and the (b) VO breeding environment (VBE) that represents "an association of organizations and a number of supporting institutions committed to a long term cooperation agreement, complying with common operation principles and infrastructures, with the main goal of increasing their preparedness towards rapid configuration of temporary alliances for collaboration in potential VOs" [35,37]. Examples of such classes are industry clusters or business ecosystems.

To enable and support this wide variety of $\mathrm{CNs}$, a substantial portfolio of models, mechanisms, tools, and platforms/infrastructures, has been developed and refined in the last years [36,38], as briefly illustrated in Figure 3. 


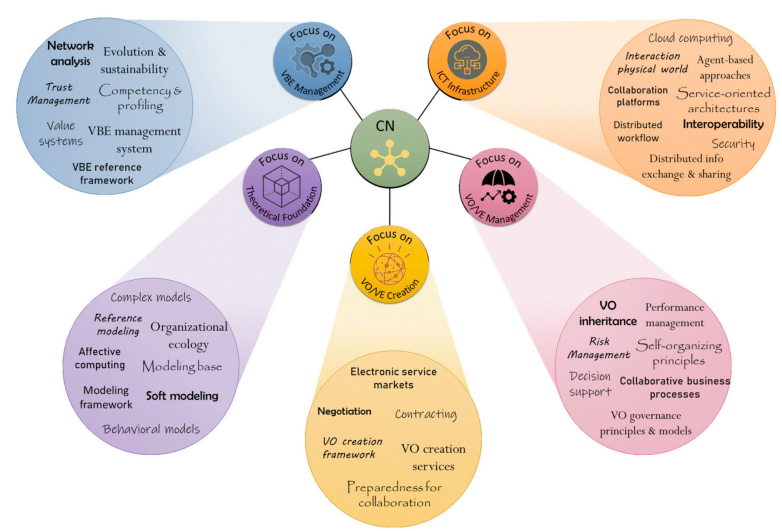

Figure 3. Collaborative networks supporting developments according to focus areas. VO: Virtual organization, VBE: VO breeding environment.

Figure 3 shows the main areas of $\mathrm{CN}$ developments which are theoretical foundation, VBE management, VO/VE creation, VO/VE management, and ICT infrastructure. Some of the main developments in each focus area include:

- Theoretical foundation: the ARCON reference model and modeling framework [39], complex models such as trust building [40], value systems [41], readiness assessment [42], and affective computing with the modeling of collaborative networked emotions [43].

- VBE management: competency models and management [44], trust building management [45], VBE management systems [46].

- $\mathrm{VO} / \mathrm{VE}$ creation: negotiation and contracting [47], $\mathrm{VO}$ creation services [48,49].

- VO/VE management: performance management [50], self-organizing principles and collaborative business processes [51].

- ICT infrastructure: interoperability [52], service-oriented architectures [53], security infrastructure and blockchain [54].

Many of the above developments were oriented to manufacturing and other industrial domains, which facilitates their adoption in Industry 4.0 and digital transformation. Further examples can be found in Section 5.

\section{Relevant Collaboration Aspects in Industry 4.0}

From the requirements to achieve Industry 4.0 and an effective digital transformation, a large number of collaboration issues can be identified. On the other hand, there are already plenty of results from the $\mathrm{CN}$ research area that contribute to solve these issues, as illustrated in Figure 3. In the following sub-sections, various relevant examples are presented which, although not comprising an exhaustive list, clearly show the role that $\mathrm{CNs}$ can have in this industrial revolution. Furthermore, as also represented in Figure 4, a number of issues requiring further research can also be identified, as summarized in Section 7, thus showing that the two areas can benefit from a kind of co-evolution process.

In order to confirm our hypothesis, this section discusses both relevant examples of required collaborative approaches in all dimensions of Industry 4.0 and identifies existing results from the $\mathrm{CN}$ domain that can support those requirements. 


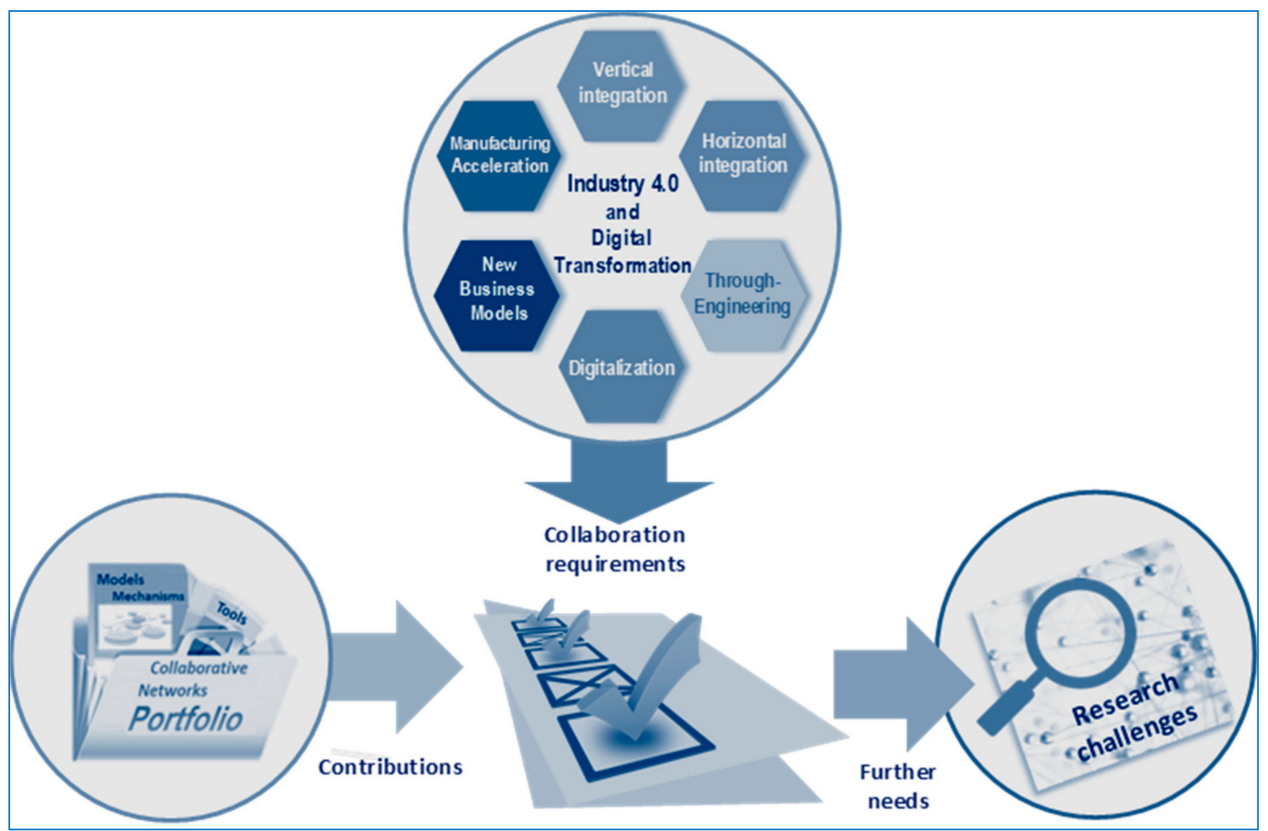

Figure 4. Industry 4.0 and collaborative networks: a co-evolution process.

\subsection{Collaboration in Vertical Integration}

Under the Industry 4.0 view, smart manufacturing enterprises are organized in multiple layers of networked and collaborative sub-systems. Departing from the traditional multi-layer view as illustrated on the left side of Figure 5, each layer becomes a collaborative network of smart components with increasing levels of intelligence and autonomy. The interactions among these layers lead to an interchange among smart production units, smart logistics, smart products, smart organizational and engineering units, and people. Collaboration among these entities is a requirement to support agile and resilient processes.
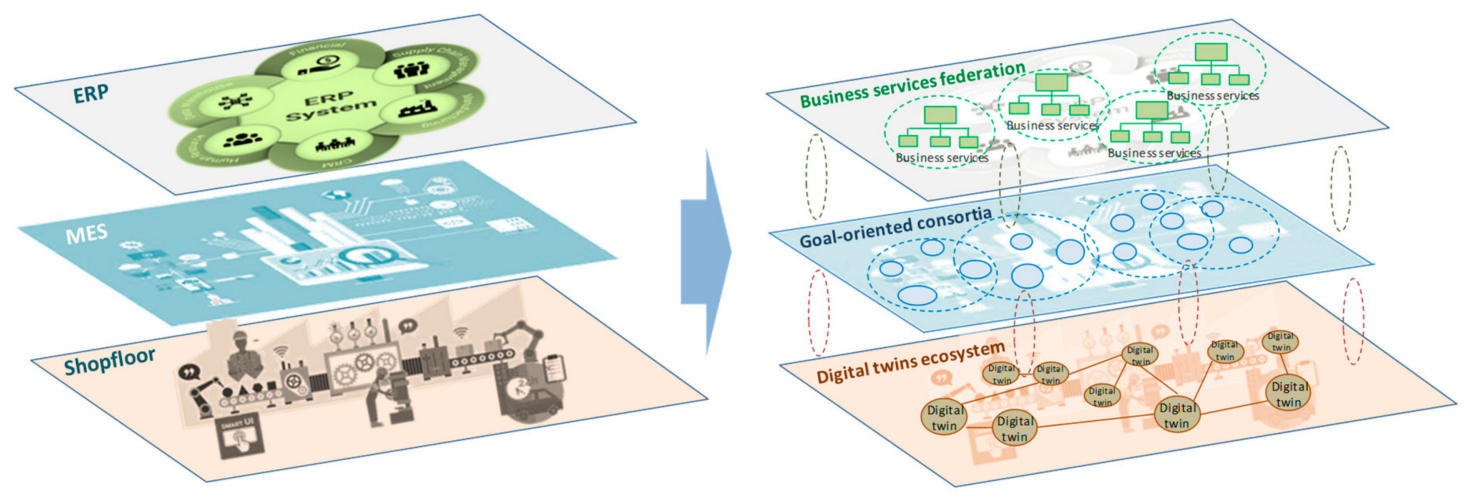

Figure 5. Collaboration in vertical integration. ERP: Enterprise Resource Planning, MES: Manufacturing Execution System

A clear example of this trend can be seen at shop floor whereas there is a progress from "control structures" to "collaborative structures". In other words, rather than looking at the shop floor as a collection of machines that (reasonably) obey to control commands, more and more these machines embed high levels of intelligence, being interconnected and represented by digital twins, and thus instead of control it makes more sense to talk about communication, coordination, negotiation, sharing, which leads to a perspective of collaboration. Therefore, we are moving from embedded and cyber-physical systems to some forms of collaborative CPS [15,55]. 
Collaborative activities between robots and humans, represented by the concept of collaborative robotics, is another recent field, although with roots in the original concept of robots [56]. This notion can be generalized to collaboration among multiple machines and humans.

Similarly, at higher abstraction layers of the enterprise architecture, the traditional monolithic complex applications tend to be replaced by federations of services provided by smart and even distributed components, each with varying degrees of intelligence.

Progress on sensorial systems and IoT facilitates real-time monitoring of processes and fluid interactions (up and downstream) among these multiple layers. The availability of large volumes of data (data-rich environments) and their access in real-time, combined with the development of enterprise-wide analytics and adoption of advanced techniques for data visualization, including virtual reality and augmented reality, also suggest collaboration among the various units of the enterprise.

What Can CNs Contribute?

Although past work on CNs mostly addressed networks of organizations or people, plenty of concepts and models can be applied to networks of machines or sub-systems, as exemplified in the following:

- Some earlier works on networks of machines [57] explored the notions of "virtual organization" and "virtual organization breeding environment" to allow agile reconfiguration of the shop floor. The idea of evolvable manufacturing system [58] also illustrates this possibility.

- Similarly, the concepts of "virtual organization" and "virtual organization breeding environment"/“business ecosystem" are being combined with CPS [55], leading to a new generation of collaborative CPS, with potential application in domains as diverse as manufacturing [59], smart buildings [15], and energy virtual power plants [60].

- A few works elaborate on the interplay among CNs, as illustrated in [61] for the case of solar energy plants.

- Organizational models for collaboration and negotiation protocols have been adopted from multi-agent systems and applied to engineering, manufacturing, and logistics [62,63]. Earlier examples can be traced back to applications in agile scheduling [64] and other more recent examples [65].

- The ideas of "sensing, smart, and sustainable enterprise", providing an integrated view of the enterprise comprehensively rely on CN concepts and mechanisms [66].

- Self-organizing concepts applied to digital transformation of manufacturing [67].

As illustrated by these examples, there is already a good mix of the two areas in terms of vertical integration.

\subsection{Collaboration in Horizontal Integration}

Increasing levels of integration and collaboration among business partners, customers, and other stakeholders (e.g., regulators, support institutions) along the value chain is a classical subject (Figure 6). Starting with the old notion of "supply chain", progressing with the challenges of "dynamic supply chains", and early focus on CNs such as "extended enterprise" and "virtual enterprise", this dimension was in fact the trigger for the emergence of the area of CNs. 
Collaboration along the value chain
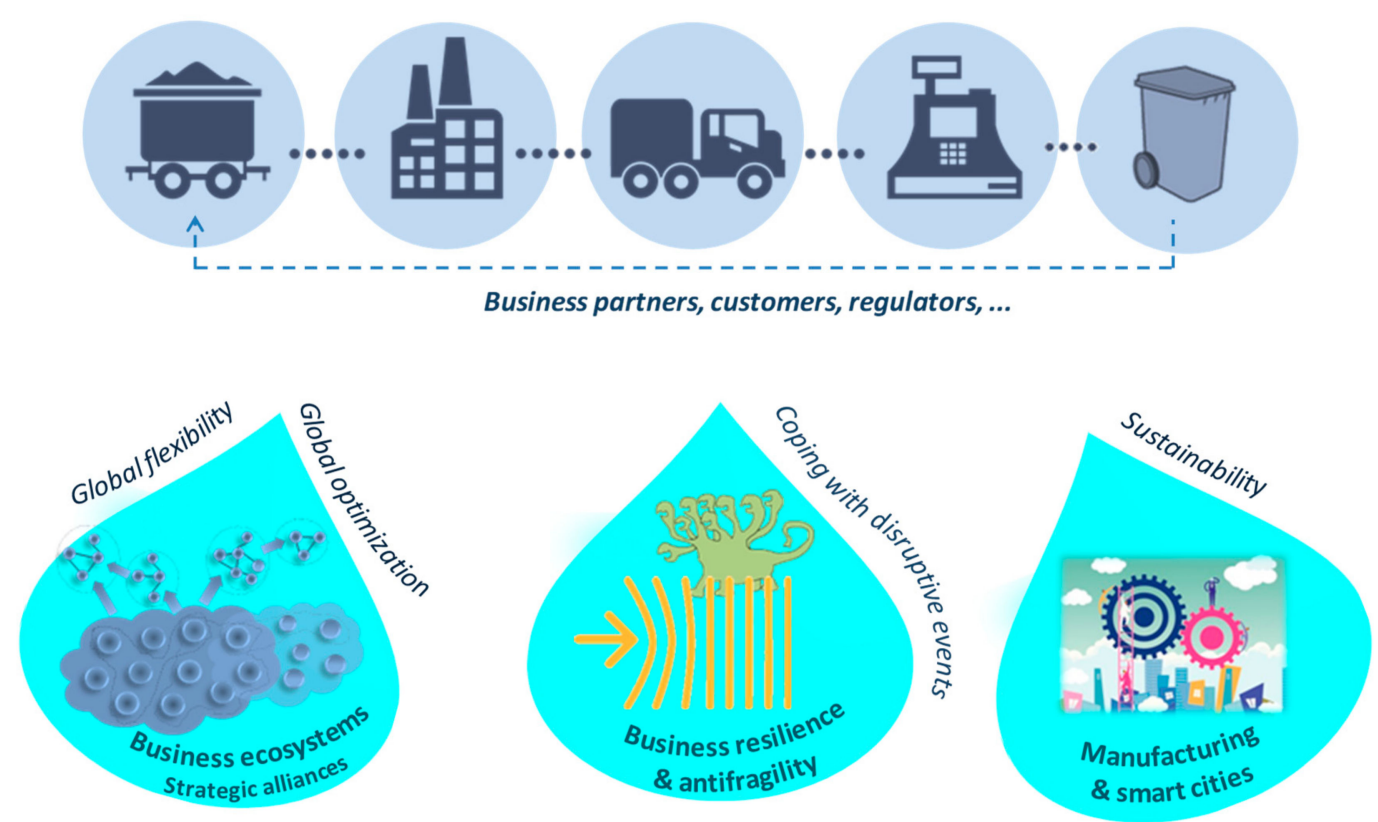

Figure 6. Collaboration in horizontal integration.

The need to share and combine information, knowledge, and other resources along the value chain, as well as developing agile coordination mechanisms to support inter-organizational processes, correspond to important facets of collaboration.

The emergence of strategic long-term alliances, such as industry clusters, business ecosystems and global value chains, requires new organizational structures and advanced models of collaboration in which global optimization, rather than enterprise-centric objectives, is pursued [35].

Flexibility and agility, as well as resilience in the face of shocks and disruptions, require the capability to rapidly form goal-oriented networks (virtual organizations) in response to turbulent and even disruptive market conditions [68].

An important sub-area that becomes more relevant when value chains become global, is transportation logistics, which typically require close cooperation of multiple operators.

Effective tracing and tracking functionalities along the value chains and products' history, which are more and more demanded for accountability and transparency, require high levels of collaboration and sharing among stakeholders.

Similarly, concerns about sustainability led to the need to consider the full lifecycle of products, including disposal and recycling, and the emergence of the circular economy [69], which again imply collaboration among all entities involved in the product lifecycle.

As a more recent trend, new models of "extreme distributed manufacturing" such as those induced by movable factories, micro-factories and 3D printing, clearly point to multi-stakeholder networks, with customers' involvement. Some recent visionary works address the combination of sustainable manufacturing and smart cities [70], which brings collaboration needs to a wider scale.

\section{What Can CNs Contribute?}

As mentioned above, this dimension has been extensively covered by $\mathrm{CN}$ research during the last decades $[32,33]$. Some examples of relevant results include:

- A variety of organizational forms, including "strategic alliances" (namely VBEs, such as "industry clusters", "business ecosystems", etc.) and "goal-oriented networks" (e.g., "virtual enterprises"/“virtual organizations") [35], and also the concept of the green VBE [71]. 
- Collaboration platforms, collaboration-support tools, and distributed information/knowledge management systems, covering the various stages of the $\mathrm{CN}^{\prime}$ s lifecycle $[35,72,73]$. Various ontologies have also been developed in support of collaboration [74].

- Collaboration-oriented governance and behavioral models for the various classes of CBNs [75-77].

- Inter-organizational workflows, distributed business processes, and business services management [78-80].

- Trust management, including models and support tools $[40,45]$.

- Reference models for CNs, such as ARCON $[39,81,82]$.

- Collaborative logistics networks $[83,84]$.

- Approaches to resilience in a CN context [68,85].

\subsection{Collaboration in Through-Engineering}

Under this dimension, at least three relevant collaboration "spaces" can be envisaged: (i) internal collaboration, (ii) external collaboration, and (iii) collaboration along the product lifecycle (Figure 7).

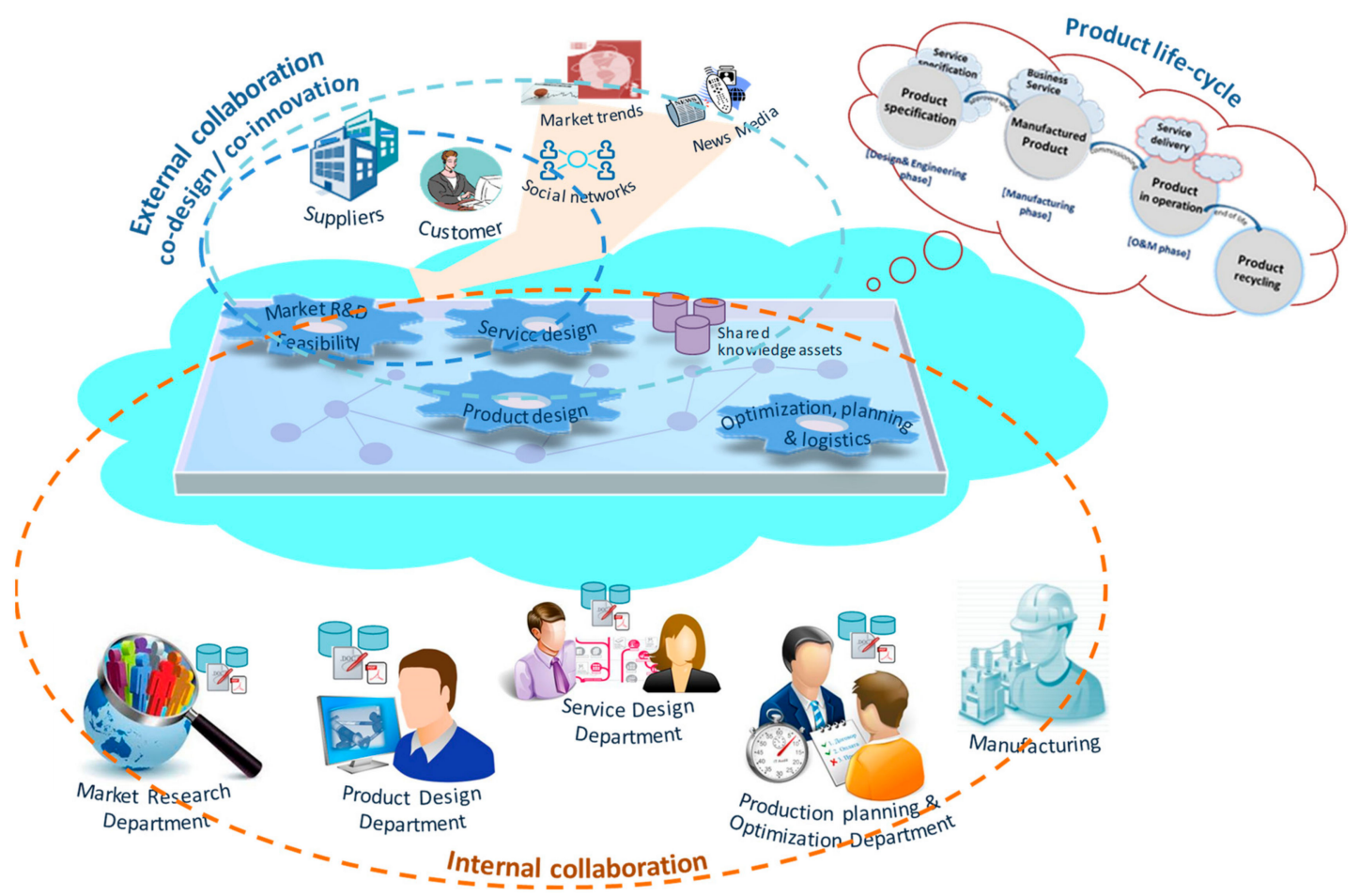

Figure 7. Collaboration in through-engineering.

Internal collaboration, a notion that can be traced back to the earlier ideas of concurrent engineering, fosters collaboration among different departments of an organization that have responsibility over the design, manufacturing, support and distribution of products.

External collaboration includes collaboration with suppliers and business partners, but also with the customer. "Service-enhanced products", i.e., adding business services to products, requires the establishment of collaborative networks of designers, manufacturers, and service providers. This need is particularly evident when the aim is to deliver integrated/value-added service packages. It is also the case when differentiation of products/services according to the geographical area of each market is needed. The growing importance of involving the customer in the process of designing new products and/or services is reflected in the "co-design"|"co-creation"/"co-innovation" concepts. This customer's involvement in co-design, together with the needed interactions among engineers belonging to different organizations of the value chain (a kind of co-engineering), demand effective support for collaboration, 
e.g., collaboration platforms, shared spaces, shared ontologies and knowledge assets. etc. Exploitation of social networks and trend analysis in media are other forms of capturing customer preferences.

When engineering considers the full lifecycle of the products and the perspective of circular economy, there is a clear need for collaboration, at different stages, among the involved stakeholders and a new perspective on engineering activities.

\section{What Can CNs Contribute?}

The adoption of collaboration platforms, often cloud-based, and CSCW (Computer Supported Collaborative Work) methods have been persistent areas of attention in the last decades. Some examples include:

- The topics of co-design, co-innovation, and establishment and leveraging of customer communities, have been addressed in multiple works in the CNs area, e.g., [86,87].

- The interactions between the lifecycles of the product/service and the interactions/ interdependencies among multiple collaborative networks were studied, namely in the GloNet project $[76,88]$.

- The role and importance of collaborative networks in supporting service-enhanced products/product-service systems have attracted considerable research attention in recent years [77,89-92].

- Tools to exploit user community networks and social media; innovation networks [93,94].

\subsection{Collaboration in Acceleration of Manufacturing}

A major transformation factor is caused by several new technologies that are entering the industry and manufacturing arenas. Some of these technologies are characterized by a very fast increase in capabilities or performance, almost following an exponential growth law, and as such named "exponential technologies".

This scenario/trend brings, as a side-effect, the need to accommodate new players, that look exogenous to the traditional manufacturing culture as they have different practices and different business cultures. Some of them lack the knowledge of established methods in manufacturing and thus the full potential of the introduction of such technologies can only be achieved when a proper combination of "new" and "traditional" methods can be pursued, which requires collaboration among very different stakeholders (Figure 8).

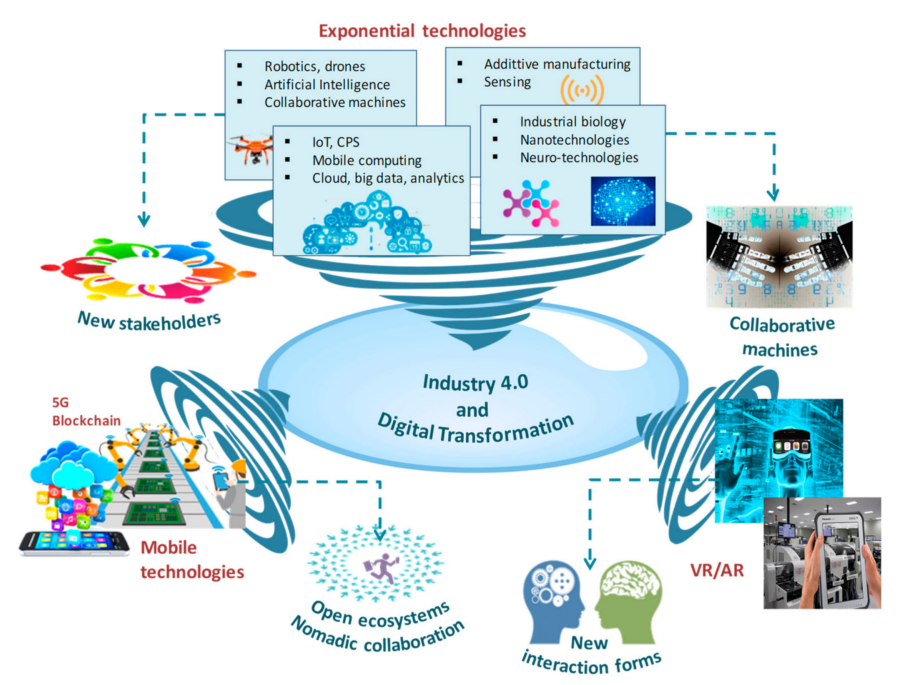

Figure 8. Collaboration in the "acceleration" of manufacturing. 
Furthermore, additive manufacturing technologies allow for higher levels of distributed manufacturing, resorting to collaboration among entities from different geographical regions and bringing a "localization flavor". Fast development in mobile and secure communication technologies, including 5G and blockchain, allows nomadic collaboration in communities with multiple degrees of membership, as well as remote interaction between people and machines/systems. Rapid penetration of AI-based technologies leads to increased levels of autonomy of machines and systems, increasingly suggesting collaboration among machines (M2M) intelligent systems, and humans. This trend involves typical collaboration-related topics such as interoperability, sharing and communication, negotiation, contracting, and trust management, among others. New forms of interaction enabled by natural user interfaces, virtual reality, and augmented reality facilitate smoother collaboration between humans and systems/machines.

\section{What Can CNs Contribute?}

Although most early works in this dimension have mainly focused on the role of specific emerging technologies and their potential impact, some research already illustrates the potential of collaborative networks as an enabler for leveraging the potential of those technologies. Examples include:

- Pursuing agility through a combination of mechanisms for dynamic consortia formation resulting from the areas of multi-agent systems [66] and CNs [47].

- Additive manufacturing/3D printing, which is often addressed only from a technological point of view, starts to be discussed as an interesting context for new collaboration models [95].

- Progress on mobile computing and connectivity concepts combined with virtual and augmented reality bring a new perspective to the way CNs are established by involving both virtual and real entities and considering nomadic collaboration [96,97].

- Human-digital twins and social dimensions in human-machine collaboration [98]. Although this subject only recently started to be discussed in the $\mathrm{CN}$ community, a number of contributions can be found in related areas. This goes from the old concept of avatar to human digital twins used in manufacturing simulation [99]. Other examples can be found in [100], in which a digital twin emulates an employee's behaviour and participates in collaborative schedule planning, or in [101] in which human digital twins are used in collaboration between humans and multi smart machines. An interesting discussion of the social dimension of the human-machine interaction (with particular emphasis on robotics), including issues of cognitive and perceptual workload, attention, trust, communication protocols, distribution of roles, etc., can be found in [98].

- Collaboration between humans and intelligent machines [102] and some suggestions on "biological transformation of manufacturing" [103].

\subsection{Collaboration in Digitalization of Products and Services}

Leveraging the full potential of the "smart product" concept requires effective collaboration among the organizations that are part of the corresponding value chain. The availability of data "next to the product" depends not only on the capabilities offered by the technical infrastructure but also on the effective collaboration among all entities with a role in the product history (Figure 9). To keep updated history records associated to the product and support tracing functionalities, it is necessary to rely on collaboration. Furthermore, the smart product itself can be used as the vehicle to mediate collaboration, implementing a kind of stigmergy [104]. In stigmergic collaboration, the communication and coordination among participants are not performed through direct interactions but rather indirectly by modifying their environment. 


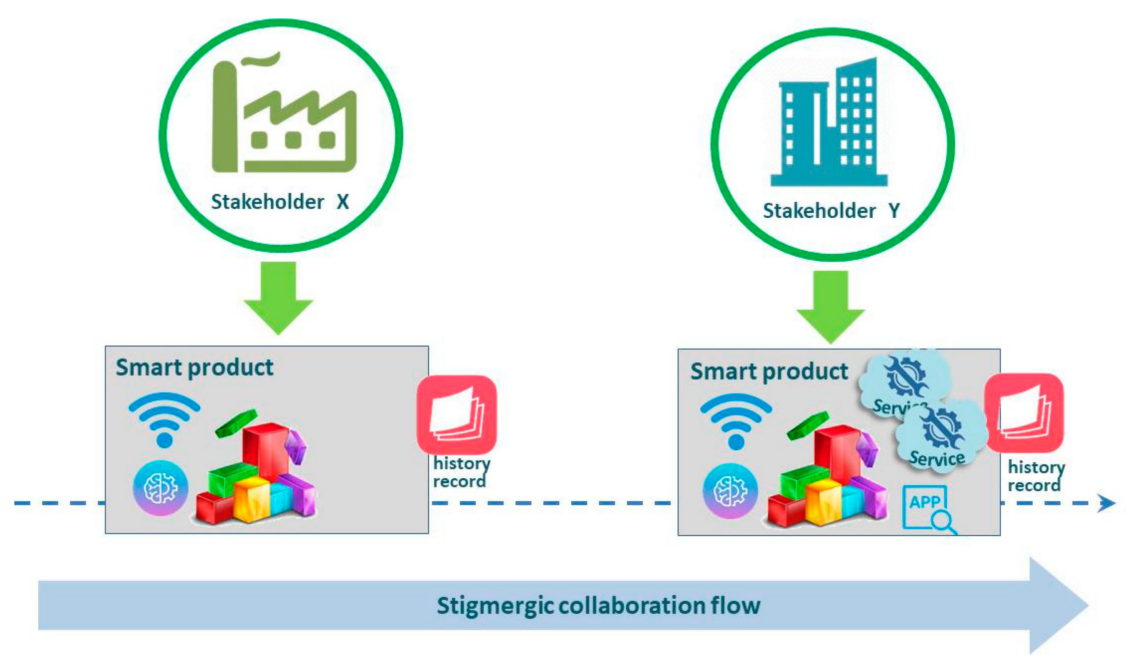

Figure 9. Collaboration in smart products and services.

The addition of user assistance, self-diagnostic, self-configurability, maintenance, and other value-added business services, which materialize the smartness of the product, naturally requires contributions from various stakeholders. On the other hand, the inherent technological features of smart products are likely to inspire the emergence of new business services that add value to those products. As such, there is an opportunity for new players, and the creation of "collaboration communities" around the product ("product-related digital ecosystems").

What Can CNs Contribute?

Although $\mathrm{CN}$ developments specifically for smart products are still not very noticeable, various other developments can have a potential application in this dimension, including:

- Various cases of "stigmergic collaboration" can be identified in the area of mass collaboration whereby "agents communicate with one another indirectly through traces left in the shared environment" [104]. Originated in the study of termites in the 1950s, this notion is now being used in the case of collaboration among large groups. Wikipedia, Digg, SETI@home, Scratch, Galaxyzoo, etc. are some of those examples [105].

- Provision of integrated business services through collaboration of multiple stakeholders has been an emphasized topic in several research works $[80,89,106]$. This includes issues such as composition of integrated services, service evolution, service discovery, etc. within collaborative environments.

- On a more general perspective, the contribution of $\mathrm{CNs}$ to the transition to service-enhanced products/product-service systems has been widely addressed [91,107,108].

- Furthermore, various works have also addressed the (potential) contribution of CNs to innovation ecosystems and open innovation [109-111].

\subsection{Collaboration in New Business Models}

The possibilities offered by ICT and mobile technologies, allowing for high levels of interconnection among people, organizations, and systems, naturally inspire the emergence of new business opportunities supported by new business models. In a way, the horizontal integration dimension is extended by exploring the potential of collaboration along the value chain. This dimension corresponds to a very dynamic area where innovative solutions are likely to emerge at a fast pace. The following examples clearly illustrate the need for collaborative approaches in this area (Figure 10):

- Collaborative engagement of customers, namely in the process of co-design/co-creation of products and services, is becoming very relevant. The term "customer intimacy" is often used to reflect 
this trend. This collaboration is not necessarily restricted to the one-to-one model, but rather extending to a community context. To improve customers' experience, especially in the context of global markets, it is also necessary to pursue close collaboration among all stakeholders in the value chain.

- Investing in global markets while considering the local specificities, as reflected in the neologism "glocal enterprise", while also satisfying higher demands for transparency and compliance, can only be effectively achieved if resorting to collaboration among global manufacturers/producers and local suppliers/service providers as well as other organizations (e.g., regulators) operating near the customer.

- Progressing towards "servitization/product-service systems" demands tight collaboration between manufacturers and service providers.

- Coping with concerns of sustainability, transparency, and increasing social responsibility, that more and more challenge the business world, require strong collaboration ties between industrial companies and other societal entities. Hybrid value chains, which combine for-profit with not-for-profit entities, are a significant example.

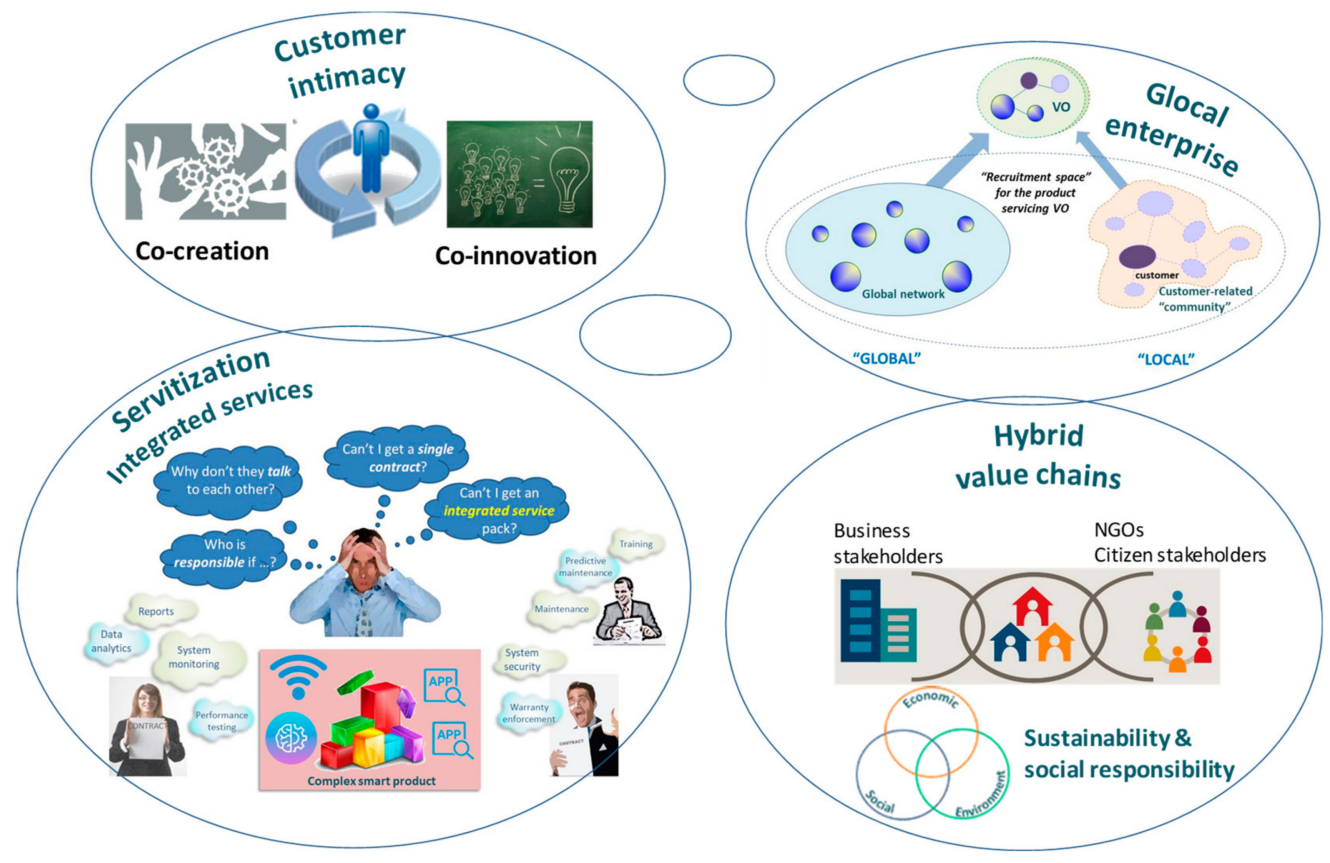

Figure 10. Examples of collaboration in new business models.

\section{What Can CNs Contribute?}

Various examples illustrate the importance of CNs contribution to new business models:

- A large variety of goal-oriented networks have been established in a wide variety of industry sectors [112], providing a good experimental basis for new developments.

- The engagement of customers in (networked) co-creation processes has been pursued in multiple areas, e.g., consumer goods sector [72,113], solar energy [86], etc. Collaboration in co-innovation and open innovation networks is also an active research topic [111].

- Collaborative networks have been suggested as an effective way for the materialization of the "glocal enterprise" concept [106].

- The contribution of CNs to the development of product-service systems/servitization has been thoroughly discussed in the literature and various demonstrative experiments have been developed [91,107]. 
- New collaboration models have been proposed for non-hierarchical and dynamic value chains [73].

- The potential contributions of CNs to sustainability can be found in various works, e.g., [66,114]. This issue has been even the main theme of some conferences [115].

- The concepts of green virtual enterprise and green enterprise breeding environment have been proposed and characterized [71].

- CNs in the implementation of the circular economy [69].

\section{Resilience and Anti-Fragility}

Contemporary industry environments, as well as society in general, face the challenge of dealing with turbulence and disruptive events that are showing with increasing frequency and potentially having extreme impacts. Such events are the result of the accumulation of a variety of factors, such as economic crises, political instability, terrorism, climate change, changes in regulations, demographic shifts, and immigration, increasing dependency on complex technologies, etc. As Taleb mentions [116], we live in the Age of Black Swans, a highly complex world characterized by unexpected events and disruptive impacts. This affects all discussed dimensions of Industry 4.0, requiring innovative approaches and new mechanisms to allow dealing with uncertainty, complexity, and non-linearities.

In this context, resilience and anti-fragility are two core characteristics that organizations can try to develop to respond positively to substantial changes in order to survive or even thrive in such a volatile world $[85,116]$. Resilience is classically understood as the capability of systems to absorb shocks and, although temporarily changing, recover from those shocks. More recently the concept evolved into the notion of transformative resilience [117], representing systems' ability to reorganize, restructure, reconfigure, and even reinvent in response to disruptions. Anti-fragility refers to the property of systems that absorb shocks and improve afterward [116]. Anti-fragility is thus a highly desirable property, which underlying mechanisms are not yet fully understood, but for which promising examples can already be found [85]. In this changing environment Industry 4.0 organizations need to build up resilience to withstand unpredictable events, remaining sustainable and maintaining their competitive advantage and profitability. Moreover, they should develop anti-fragility in order to improve and explore opportunities in disruptive contexts.

The innovation and artificial intelligence principles associated with Industry 4.0 developments, coupled with the different tools and methodologies adopted in the digital transformation should enable organizations to prepare for, resist, and rapidly recover from detrimental impacts of disruptive events. The target environment aimed at should have the potential to embrace stressors and help to reinforce the overall resilience and anti-fragility of organizations through characteristics like self-optimization, and real-time decision-making [118]. Indeed, the development of Industry 4.0 creates the opportunity to further develop resilience/anti-fragility-related capabilities. These capabilities are attributes that enable companies and business ecosystems to anticipate potential threats, be prepared for change and unpredictable incidents, mitigate the effects of adverse events, and be able to adapt their behavior following a disturbance. Examples of such relevant capabilities include flexibility, redundancy, agility, visibility, and adaptability. Through proper design principles the ongoing digital transformation needs to aim at engineered systems that can achieve/improve these characteristics to be able to resist change, and autonomously recover from disruptive situations $[85,118]$. Table 2 gives examples of these relevant resilience/anti-fragility related capabilities. 
Table 2. A sample of resilience/anti-fragility-related capabilities.

\begin{tabular}{|c|c|}
\hline Capabilities & Description \\
\hline Agility & Ability to respond to unpredictable changes quickly and gracefully [85]. \\
\hline Adaptability & Ability to modify operations to fit occurring changes [118]. \\
\hline Cognitive ability & $\begin{array}{l}\text { Ability to sense and acquire knowledge through experiences helping } \\
\text { self-learning and complex problem solving [119]. }\end{array}$ \\
\hline Efficiency & $\begin{array}{l}\text { Ability to make best use of production resources and reduce costs through } \\
\text { smart ways of doing things in order to respond to an unexpected shortage of } \\
\text { resources [118]. }\end{array}$ \\
\hline Flexibility & $\begin{array}{l}\text { Capability to adjust to changing work to ensure that changes caused by } \\
\text { a disruptive event or customer demand can be handled successfully [85]. }\end{array}$ \\
\hline Fault tolerance & $\begin{array}{l}\text { Enabling continuous system operation to a level of satisfaction when one or } \\
\text { more of a system's components fail [120]. }\end{array}$ \\
\hline Redundancy & The presence of multiple assets/sources/components to cope with failures [85]. \\
\hline Security compliance & Capability to defend against cyber threats, vulnerabilities, and risks [118]. \\
\hline \multirow[b]{2}{*}{ Self-* properties } & $\begin{array}{l}\text { Abilities of systems to automatically protect themselves against } \\
\text { failures [119], including: }\end{array}$ \\
\hline & $\begin{array}{l}\text { - Self-management: The capability of a system to reconfigure itself in } \\
\text { response to external changes. } \\
\text { - Self-adaptation: Ability to adjust parameters in response to changes. } \\
\text { - Self-healing: Ability to detect faults and take corrective actions. } \\
\text { - Self-organizing: Ability to change system's topology to create new } \\
\text { features to meet different requirements. }\end{array}$ \\
\hline Visibility & $\begin{array}{l}\text { Awareness of the status of all variables (products and environment) to } \\
\text { minimize vulnerabilities, to make more informed and precise decisions in real } \\
\text { time, predict issues, and self-optimize as problems occur [85]. }\end{array}$ \\
\hline
\end{tabular}

Furthermore, to help organizations become less vulnerable to unpredictable changes, there is a need to define, at the governance level, adequate strategies to cope with disruptions effectively and timely through well-devised activation of existing capabilities. Resilience-focused strategies are those that help a system in recovering from shocks and returning to an acceptable state in the face of disruptions; anti-fragility approaches, on the other hand, are those that contribute to gain the advantage of disorders to improve [85].

Collaboration has been pointed out as one of the most promising strategies to handle disruptive events [68]. A CN perspective can strengthen the business environment in a context of market turbulence namely through supporting an agile combination of competences, facilitating sharing information, resources, and risks in time of crisis. Literature shows the important role of different classes of CNs in rapidly respond to business opportunities in a volatile business environment e.g., through the creating of dynamic goal-oriented consortia. Indeed, developing collaborative relationships can enhance resilience by facilitating effective contingency planning and risk sharing among partners. For instance, activities such as product lifecycle management, collaborative forecasting, negotiation, information sharing, resource exchange, collective cognitive systems, or knowledge co-production, lead to high levels of coordination and positive performance when dealing with disruptions. As such, it is argued that in the case of market changes or disruptive events, collaborative activities can prevent opportunism by promoting trust and knowledge exchange between organizations. In particular in the context of collaborative business ecosystems [50], the establishment of dynamic collaboration ties among organizations, creating "pools" of shared competencies and assets, offers a promising approach to increase organizations' agility, share risks, and thus better cope with unforeseen disruptive events. Table 3 shows some other relevant resilience/anti-fragility aiming strategies that are about getting real-time data and combine with different advanced technologies to help organizations survive, adapt, 
and seize the opportunity to grow in changing environments [118]. Further examples can be found in [85].

Table 3. A sample of resilience/anti-fragility support strategies.

\begin{tabular}{|c|c|}
\hline Strategies & Description \\
\hline Collaboration & $\begin{array}{l}\text { Working together to better manage disruptions through exchanging } \\
\text { data, resources, and ideas (collaborative problem solving) [118]. } \\
\text { Examples: risk sharing, information sharing, trust building among } \\
\text { partners, negotiation, plug and play teaming, and product } \\
\text { lifecycle management. }\end{array}$ \\
\hline Fault Injection & $\begin{array}{l}\text { A test-based approach for evaluating survivability of a system, by } \\
\text { intentionally injecting faults to a system to ensure it can tolerate and } \\
\text { recover from error conditions [120]. Examples: Simian Army, GameDay. }\end{array}$ \\
\hline Fail Fast & $\begin{array}{l}\text { To quickly fail deliberately (when the impact is small) to learn from } \\
\text { failures [121]. }\end{array}$ \\
\hline Feedback Mechanism & $\begin{array}{l}\text { To maintain the system's stability and prevent problems by comparing } \\
\text { its status with reference values to know if it is necessary to make } \\
\text { a modification [85]. }\end{array}$ \\
\hline Graceful Degradation & $\begin{array}{l}\text { Allowing to work with limited functionality to prevent entire system's } \\
\text { downtime [85]. }\end{array}$ \\
\hline & $\begin{array}{l}\text { Deciding on the structure, volume, location, and capacity of systems } \\
\text { through different strategies such as [85]: }\end{array}$ \\
\hline Network Structure Planning & $\begin{array}{l}\text { Fragmentation, which is related to decentralization } \\
\text { and distribution. } \\
\text { Modularity, consisting of separate linked components to reduce } \\
\text { complexity and change immediately. } \\
\text { Integration, a combination of subsystems, resources, processes, etc. } \\
\text { to facilitate agility and flexibility. }\end{array}$ \\
\hline Optionality Creation & $\begin{array}{l}\text { Having lots of options to experiment with uncertainty that gives } \\
\text { freedom to respond to unforeseen circumstances and benefit from } \\
\text { opportunities [116]. }\end{array}$ \\
\hline Real-time Monitoring & $\begin{array}{l}\text { To observe, and optionally signal alarms on the state of the system for } \\
\text { quicker responses to problems and even predictive maintenance [120]. }\end{array}$ \\
\hline Swarming & $\begin{array}{l}\text { Increasing the resilience of a system by decentralized coordination and } \\
\text { extending the concepts of self-organizing and self-synchronization by } \\
\text { real-time information sharing [119]. }\end{array}$ \\
\hline Weak links & $\begin{array}{l}\text { A lower level of connection between components in order to stop } \\
\text { propagation failures [121]. }\end{array}$ \\
\hline
\end{tabular}

Although this topic is attracting the growing attention of the research and business communities, many of the identified strategies have been applied to very specific cases, and a sound understanding of their applicability and underlying context is still lacking.

\section{Discussion of New Research Challenges}

Past initiatives in $\mathrm{CN}$ research and industrial development led to a large portfolio of theoretical models, mechanisms, and empirical knowledge, which can provide good contribution to the identified collaboration requirements of the ongoing industrial revolution, as summarized above. Furthermore, the catalytic effect of Industry 4.0, acting as a melting pot for the convergence of multiple knowledge areas, and the digital transformation "movement", raise new research challenges, eventually leading to Collaborative Networks 4.0. These challenges are illustrated by the following list, which results from various inputs, namely (1) identified gaps in the literature and trends analysis, (2) acquired experience in various related research projects, and (3) a synthesis of ideas discussed in recent international conferences (e.g., the editions PRO-VE and DoCEIS of the last 3 years). The challenges identified are 
not specific of any singular dimension of Industry 4.0; rather most of them cross various dimensions. As such, the adopted structure was to group them by thematic proximity.

\section{(a) Extended scope}

\section{Extend the $\mathrm{CN}$ perspective to complex CPS}

Context: Previous works on CPS/IoT have been mostly focused on the core technological issues, e.g., interconnectivity, integration platforms, safe communications and protocols, control, and approaches to cope with limited energy, computing and communication capabilities. When facing (1) increasing levels of intelligence and autonomy of smart objects, devices, machines, and systems, and (2) an exponential growth of the number of interconnected entities, there is a need to adopt new organizational and control approaches to such systems.

\section{Further research:}

Moving towards the notion of collaborative CPS [55], including topics such as:

- Rethinking the organizational structure of CPS as a collaborative network, e.g., ecosystems of smart entities.

- Further development of the notion of "digital twins" to embed the collaboration perspective, namely when considering higher levels of intelligence and autonomy of sub-systems.

- In terms of governance, progress from a "control-orientation" towards a "collaboration-orientation", allowing entities to engage in coordination, sharing, negotiation, and contracting.

Extend the $\mathrm{CN}$ perspective to Human-Machine (H-M) collaboration and communities of machines

Context: The emerging area of "collaborative robotics" already points to hybrid forms of collaboration. However, rather than a "one-to-one collaboration" case, as addressed in contemporary systems [49], one can envision more extended networked scenarios, eventually involving multiple machines and humans [101]. Complementarily, new user interfacing technologies, such as the so-called "natural user interfaces", and virtual and augmented reality, allow for the development of more effective ways of human-machine collaboration.

Further research:

Pursuing a hybridization of social interactions, namely through:

- Taking advantage of new user interfacing technologies to better allow collaboration between humans and machines/systems, somehow revisiting the earlier concept of "balanced automation systems" [122,123].

- Explore affective computing [124] and emotions in CNs [43] to reach "more natural" forms of collaboration.

- Extending the notion of persona to "human digital twin", to both re-enforce the collaboration perspective (e.g., supporting preparatory tasks for collaboration and intermediation) and contribute to human enhancement (a kind of human-machine symbiosis).

- Supporting not only H-M but also Machine-Machine (M-M) collaboration, as machines become smarter.

- Finding ways to deal with technological evolution and still-in-use obsolete autonomous systems. 


\section{Seek inspiration from Nature}

Context: Nature, in its various areas, is full of successful collaboration cases. These cases show in a large variety of forms and appear to be highly optimized and sustainable [36]. Concomitantly, a core goal of digital transformation is to seek optimized, agile, and sustainable solutions.

Further research: Adopting findings from Nature-related disciplines on collaboration cases and taking them as a source of inspiration to:

- Better understand collaboration mechanisms, processes, and behaviors of actors involved.

- Replicate collaboration mechanisms and effective organizational structures, towards sustainable and optimized solutions.

More detailed examples of such additional research can be found in [36].

(b) Organizational models

\section{Combination of and interaction among multiple dynamic networks}

Context: The various integration dimensions of Industry 4.0 and the need to support the full lifecycle of products induce the co-existence in the same environment of multiple networks, composed of organizations, people, machines, and smart systems, which have multiple interaction points, even some that overlap. Some of these networks are formal, regulated by contracts, while others are informal. Furthermore, these networks are characterized by different durations and co-exist at different stages of their lifecycles. Understanding this reality is essential for achieving effectiveness, flexibility, agility, sustainability, and resilience of the next industrial systems. Various efforts in this direction can already be found in [61], but the topic remains a key research challenge.

Further research: Understanding and developing support for the interdependences among co-existing networks, including:

- Extension of existing reference models to cope with inter-dependent and co-existing networks.

- Development of adequate governance models for interacting networks.

- Development of platforms supporting the participation of entities in multiple networks.

- Better understanding self-organizing and co-evolution principles.

- Handling power dynamics, intellectual property and ownership.

- Networks involving hybrid value systems

Context: The increasing demand for an organization's commitment to social responsibility and the need for systems' sustainability require new levels of collaboration between manufacturing companies and other societal actors. Collaboration among entities of the public and private sectors, including non-governmental organizations (NGOs), necessarily involves different value systems. Furthermore, communities and smart cities need to consider and nourish the contribution of the manufacturing sector to the wealth of the regions/country, thus calling for a "healthy co-existence".

Further research: Achieving a clear understanding of the issues involved when combining and aligning different value systems. This also includes aspects such as expectations, incentives, ethics, value distribution, open innovation, etc. 
(c) Smartness and data-richness

\section{- Dealing with data-rich environments}

Context: An important vector of the digital transformation are the fast-increasing volumes of data resulting from the large usage of sensors and smart objects/smart devices, as well as the hyper-connectivity of people, organizations, and (smart) systems. These new data-rich environments enable better decision-making and the development of systems but also challenge the collaborative networks design and management. Since previous frameworks were constrained by data scarcity, existing models need to be reconsidered, possibly giving birth to new system architectures, principles, mechanisms, and processes.

Further research: Developing new "collaborative business services" that reveal and explore the value of "data-rich environments" and "big data" as well as new decision-making support mechanisms. A vast array of sub-topics become relevant here, including:

- Adoption of proper data analytics and machine-learning tools.

- Value of data and ownership.

- Traceability and transparency along the whole value chain and whole lifecycle of products/services.

- Cybersecurity and data protection in collaborative environments.

- Facing increasing uncertainties, fake data/data quality, and complexity.

\section{- Further development of the smartness and sensing dimensions}

Context: Innovative products, processes, infrastructures, organizations, and business communities are increasingly being designed to be "sensing, smart, and sustainable (S3)", i.e., further extending the notion of the "S3 enterprise" [66]. Inter-connected smart devices and sensor networks enable new levels of context awareness. Increased computational power, combined with the application of learning algorithms to data-rich environments, allows the smartness and self-adaptability and evolutionary capabilities of systems, components, and products (smart products) to be increased, giving rise to a combination of distributed intelligence with CNs.

Further research: Developing cognitive collaborative networks with evolving capabilities. In other words, leveraging the capabilities of AI and machine learning to bring collaborative systems to a form of collective intelligence and shared situation awareness (a form of what is called "distributed cognition" in cognitive sciences). Through learning, such systems shall be able to not only acquire new knowledge, but also adapt to changing environments, which is particularly relevant to contexts of market turbulence.

- Further exploitation of open "linked data" and interlinking of open ontologies

Context: As the availability of heterogeneous data and knowledge sources increases in hyper-connected contexts, interlinking those data and that knowledge is important to enhance collaboration among participating actors in industry environments. Such interlinking is crucial namely in the context of the vertical and horizontal integration dimensions.

Further research: Experiment and assess methods for "open linked data", visualization techniques, and collaborative interlinking of and refinement of ontologies. 
(d) New business models and strategies

\section{- New collaborative business models:}

Context: Synergies created by the convergence of multiple technologies involved in Industry 4.0 and related digital transformation are triggering and inspiring new value co-creation mechanisms and collaborative business models. Organizations (public, private, or hybrid) are challenged to redesign their strategies, their collaboration rules, and processes, as well as their interactions with the surrounding environment (e.g., with the regulatory systems).

Further research: Developing and evaluating new collaborative business models considering new organizational structures and the possibilities offered by new technologies. Examples of associated topics include:

- Keeping a radar on emerging business models and experiences and assessment of lessons learned.

- New models of collaboration at strategic level, approaches to select and align collaboration strategies, and focus on agile business models.

- Analysis and management of collaboration risks, modelling of uncertainty and its propagation over collaborative networks.

- Trust management associated to new business models.

- Models of benefits distribution, risk and responsibility sharing.

- Combination of new collaborative business models with issues of social responsibility, ethical models, and compliance with regulatory frameworks.

\section{- Monetization of collaboration}

Context: Although plenty of arguments can be found in literature on the benefits of collaboration, it is also often seen as a burden due to the extra overheads e.g., communication efforts, alignment of strategies and work methods, etc.) and specific skills that collaboration requires. It is thus necessary to find ways of making benefits (value generated by collaboration) more explicit and quantifiable.

Further research: Developing appropriate indicators and metrics that make the value of collaboration explicit and measurable. It is also interesting, from a $\mathrm{CN}$ governance perspective, to study how the adoption of specific indicators can affect the behavior of network members.

\section{(e) Resilience and sustainability}

\section{Approaches for resilience and anti-fragility in collaborative networks}

Context: The current business world and society in general face major turbulence, having to cope with an increasing number of disruptive events of large impact. In such context, the sustainability of business ecosystems and other collaborative networks depends on finding appropriate approaches to cope with disruptions (be resilient) and even trying to "become" stronger after a disruption (be antifragile) [116].

Further research: Finding novel approaches and strategies to implement resilience and anti-fragility in collaborative networks context. This needs to be complemented with the design of proper assessment indicators.

\section{a Better understand the collaboration-competition interactions}

Context: Despite the growing hyper-connectivity and the increasing wide-spreading of the business ecosystems concepts, often collaboration-competition tensions between agents co-exist in the same environment, as represented by the term "coopetitive environment". 
This requires the development of better understanding of collective behaviors and collective emotions in order improve sustainability.

Further research: Developing advanced behavioral models for collaborative networks, including incentives and expectations management.

- Further develop the sustainability dimension

Context: Sustainability is nowadays a major challenge for all industrial sectors. This is directly reflected in the efforts to improve processes and usage of resources, reducing the ecological footprint as well as coping with related directives from governments and other international bodies. The development of concepts such as circular economy is also a result of this trend. Collaborative networks have been pointed out as an important enabler for the effective implementation of such concepts [114], which require collaboration among multiple heterogeneous, autonomous, and distributed stakeholders. Furthermore, there is a need for a smooth combination of human capabilities and artificial intelligence within industrial systems in order to reach improved efficiency and better working conditions.

Further research: Address sustainability issues at all layers of the manufacturing systems, from the shop floor to the production management systems and value-chain networks. This aim includes:

- Progressing from an "enterprise-centric perspective" towards a "business ecosystem-oriented perspective".

- Aligning developments with the objectives of the UN Agenda 2030 for sustainable development [125].

- Increasing collaboration with other knowledge areas, such as environment engineering and social innovation.

\section{(f) Collaboration support platforms}

\section{- New generation of collaboration platforms}

Context: Several core technologies for the digital transformation such as cloud computing, IoT, CPS, big data, sensing, AI/machine learning, mobile computing, etc., have reached a good level of maturity and are quickly being adopted in industrial contexts. This creates the opportunity to design and develop new integration and collaboration methods leveraging the synergies brought in by these technologies. In addition to new support to data collecting, analysis and visualization, knowledge extraction, and real-time context awareness, the inclusion of cognitive engineering components, intelligent assistants, data service agents, crowd-based collaboration support, and decision support and problem-solving mechanisms, exploring massively connected/linked data, opens up new avenues for collaborative environments supporting collaboration of entities located around the world.

Further research: Exploiting opportunities opened by the new technologies to support new collaboration environments coping with higher levels of connectivity, distributed intelligence/smartness of sub-systems, new actors of very diverse nature, highly dynamic contexts, and overlapping networks.

- Enhanced human-system interaction support

Context: Increasing usage of simulation, virtual reality/immersive technologies, and augmented reality in practical industrial applications. Furthermore, there is an increasing demand to improve user experience/customer intimacy. 
Further research: Exploiting the functionalities of new technologies to create more "natural" forms of interaction between humans and systems/machines, allowing higher levels of hybrid collaboration. Related topics include:

- Use of virtual reality, augmented reality, and natural user interfaces to enhance human-machine/system collaboration.

- Human digital twins to reduce the costs of collaboration (a kind of collaborationoriented avatars).

- Use of virtual reality, augmented reality, and natural user interfaces to enhance customer experience with products and services.

- New levels of tele-presence/remote interaction, adopting technologies from gaming and tele-robotics to distributed manufacturing systems.

\section{- Improved service specification mechanisms}

Context: Strong trend towards servitization.

Further research: Enhancing mechanisms for service discovery, service selection, service composition, and service evolution within collaborative network contexts. This also involves issues such as:

- Coping with evolution of equipment and sub-systems.

- Coping with mobility (nomadic collaboration).

- "De-construction" of traditional software systems and moving to shared libraries of algorithms/services.

- On-the-fly orchestration of services.

- Collaborative service design.

- Improved cyber-security

Context: Cyber-security has always been a key topic in $\mathrm{CNs}$ research, namely in terms of safe communications, access rights and protection of shared repositories, digital certificates, user authentication, non-repudiation, and some forms of digital institutions (e.g., e-notary). With the increasing hyper-connectivity, "hybridization" of networks, evolution and co-existence of multiple networks with shared members, both complexity and cyber-risks greatly increase.

Further research: Finding new ways of managing cyber-risks in hyper-connected collaborative environments. Examples of relevant sub-topics include:

- Application and evaluation of distributed ledger-type of technologies.

- Novel electronic institutions.

- Risk propagation and counter-attack strategies.

\section{(g) Collaboration culture and awareness}

\section{- Strengthen interdisciplinary work}

Context: The inclusion of new players, namely those coming from the exponential technologies [126], combined with the high integration levels promoted by Industry 4.0, clearly rely on synergies resulting from the combination of contributions from a variety of knowledge areas. The collaborative networks discipline is by itself the result of interdisciplinary efforts, but this effort needs to be further pursued bearing in mind the ongoing digital transformation. 
Further research: Continuously re-enforce multi-disciplinary and interdisciplinary approaches, seeking synergies from the combination of multiple knowledge areas and diversity of players.

- Further education and dissemination of a collaboration culture

Context: The effectiveness of the aimed industrial revolution does not only depend on technology. It requires new ways of working, the adoption of new methods and new processes, with a different mind-set, thus a "new collaboration culture". For a successful transformation journey, it becomes mandatory to create a "culture of collaboration" in industry and society.

Further research: Establishing educational curricula on collaborative networks and elaborating a portfolio of success stories of collaboration.

- Responsibility, ethics and compliance

Context: Various earlier works on CNs focused on the needed legal frameworks to regulate their establishment and operation. Some countries (e.g., Portugal, Italy and some others) already have some laws covering both "long-term strategic networks" and "goal-oriented networks". With the increasing hyper-connectivity and systems integration (towards systems-of-systems), and the increasing levels of intelligence and autonomy of those systems, it is necessary to revisit and better understand issues of responsibility, compliance and ethics, and define novel regulatory mechanisms and frameworks.

Further research: Developing new conceptual and regulatory frameworks to cope with responsibility, ethics, and compliance in hyper-connected systems with increasing levels of intelligence and autonomy.

The above list of challenges, although not exhaustive, provides a representative overview of the new directions for research resulting from the "coming together" of CNs and digital transformation/Industry 4.0. As this list not only emerges from the identified gaps in literature but also reflects, to a large extent, the outcomes from multiple discussions in a series of international events organized by SOCOLNET (Society of Collaborative Networks), it demonstrates that the area has become an active research agenda for the coming years.

\section{Conclusions}

The aims and vision of Industry 4.0 and its related term smart manufacturing, supported or enabled by the convergence of various new technologies, is having a strong transformation effect and mobilizing significant efforts towards a reorganization and even revitalization of industry. As advocated by many authors, the effects of this transformation are leading to a new "industrial revolution". Furthermore, the same ideas and the associated digital transformation process are now emerging in many other sectors of society.

From our perspective, an effective implementation of these ideas strongly relies on new organizational forms, mechanisms, and processes with a collaborative nature. This perspective is sustained by the results of an extensive analysis of requirements of Industry 4.0, namely digging into its main dimensions, i.e., vertical integration, horizontal integration, through-engineering, acceleration of manufacturing, digitalization, and new business models, from which a vast collection of collaboration-related issues could be identified. Furthermore, and crossing all dimensions, the need to cope with a context of turbulence and increasing frequency of disruptive events also re-enforces the importance of $\mathrm{CNs}$ in the development of resilience and anti-fragility-oriented strategies.

From the analysis of literature on $\mathrm{CNs}$, it becomes clear that a large portfolio of research results and empirical knowledge has been developed during the last few decades, constituting a valuable 
contribution to the aforementioned collaboration-oriented needs, and thus placing Collaborative Networks as a pillar for Industry 4.0 and digital transformation.

Furthermore, an analysis of gaps found in literature and the outcomes of various discussion panels and brainstorming sessions organized at the PRO-VE and DoCEIS conferences during the last three years show that the ongoing digital transformation also suggests additional research challenges and/or back-up of current research topics in the $\mathrm{CN}$ community. As such, a comprehensive, although incomplete, list of further research challenges was elaborated, showing the advantage of considering a co-evolution of the two areas.

Author Contributions: Conceptualization, L.M.C.-M.; methodology, L.M.C.-M. and R.F.; writing-drafting Section 3, R.F. and L.M.C.-M.; writing-drafting Section 4, F.F. and L.M.C.-M.; writing-drafting Sections 5 and 7, L.M.C.-M.; writing-drafting Section 6, J.R. and L.M.C.-M.; writing-inputs for Sections 1 and 8, all authors; writing—reviewing and editing, all authors; funding acquisition, L.M.C.-M.

Funding: This work was funded in part by the Portuguese "Fundação para a Ciência e Tecnologia" "Strategic program UID/EEA/00066/2019" (CTS project), by the SOCOLNET society (ARCON-ACM project), and by the project POCI-01-0247-FEDER-033926 (Future Yammi).

Acknowledgments: The authors thank the valuable contributions of the attendants of the PRO-VE and DoCEIS conferences in the editions of 2017, 2018, and 2019 for the discussion and consolidation of ideas in the various panels and discussion sessions.

Conflicts of Interest: The authors declare no conflict of interest.

\section{References}

1. Gilchrist, A. Industry 4.0-The Industrial Internet of Things; Apress: Bangken, Thailand, 2016. [CrossRef]

2. Bartodziej, C.J. The Concept Industry 4.0-An Empirical Analysis of Technologies and Applications in Production Logistics; Springer Gabler: Wiesbaden, Germany, 2017. [CrossRef]

3. EFFRA. Factories of the Future: Multi-annual Roadmap for the Contractual PPP under Horizon 2020. European Commission, 2013. Available online: https://www.effra.eu/sites/default/files/factories_of_the_ future_2020_roadmap.pdf (accessed on 20 September 2019).

4. Monostori, L. Cyber-physical Production Systems: Roots, Expectations and R\&D Challenges. Procedia CIRP 2014, 17, 9-13. [CrossRef]

5. Uhlemann, T.; Lehmann, C.; Steinhilper, R. The Digital Twin: Realizing the Cyber-Physical Production System for Industry 4.0. Procedia CIRP 2017, 61, 335-340. [CrossRef]

6. Kang, H.S.; Lee, J.Y.; Choi, S.; Kim, H.; Park, J.H.; Son, J.Y.; Kim, B.H.; Noh, S.D. Smart manufacturing: Past research, present findings, and future directions. Int. J. Precis. Eng. Manuf. Green Tech. 2016, 3, 111-128. [CrossRef]

7. Camarinha-Matos, L.M.; Fornasiero, R.; Afsarmanesh, H. Collaborative Networks as a Core Enabler of Industry 4.0. In Collaboration in a Data-Rich World; PRO-VE 2017. IFIP AICT 506; Springer: Cham, Switzerland, 2017; pp. 3-17. [CrossRef]

8. Drath, R.; Horch, A. Industrie 4.0: Hit or Hype? IEEE Ind. Electron. Mag. 2014, 8, 56-58. [CrossRef]

9. Sniderman, B.; Mahto, M.; Cotteleer, M.J. Industry 4.0 and Manufacturing Ecosystems-Exploring the World of Connected Enterprises; Deloitte University Press: New York, NY, USA, 2016; Available online: https://dupress.deloitte.com/content/dam/dup-us-en/articles/manufacturing-ecosystemsexploring-world-connected-enterprises/DUP_2898_Industry4.0ManufacturingEcosystems.pdf (accessed on 9 March 2017).

10. Hermann, M.; Pentek, T.; Otto, B. Design Principles for Industrie 4.0 Scenarios. In Proceedings of the 49th Hawaii International Conference on System Sciences (HICSS), Koloa, HI, USA, 5-8 January 2016; pp. 3928-3937. [CrossRef]

11. Petersen, K.; Vakkalanka, S.; Kuzniarz, L. Guidelines for conducting systematic mapping studies in software engineering: An update. Inf. Softw. Technol. 2015, 64, 1-18. [CrossRef]

12. Camarinha-Matos, L.M.; Afsarmanesh, H. A Roadmapping Methodology for Strategic Research on VO. In Collaborative Networked Organizations-A Research Agenda for Emerging Business Models, cap. 7.1; Kluwer Academic Publishers: Boston, MA, USA, 2004. [CrossRef] 
13. Camarinha-Matos, L.M.; Afsarmanesh, H.; Ferrada, F.; Oliveira, A.I.; Rosas, J. A comprehensive research roadmap for ICT and ageing. Stud. Inform. Control 2013, 22, 233-254. [CrossRef]

14. Martinez Hernandez, V.; Neely, A.; Ouyang, A.; Burstall, C.; Bisessar, D. Service Business Model Innovation: The digital Twin Technology. In Proceedings of the EurOMA Conference, Hungary, Budapest, 24-26 June 2018. [CrossRef]

15. Nazarenko, A.; Camarinha-Matos, L.M. Basis for an Approach to Design Collaborative Cyber-Physical Systems. In Proceedings of the Technological Innovation for Industry and Service Systems, Costa de Caparica, Portugal, 8-10 May 2019; Springer: Cham, Switzerland, 2019; Volume 553, pp. 193-205. [CrossRef]

16. Schlaepfer, R.C.; Koch, M.; Merkofer, P. Industry 4.0-Challenges and Solutions for the Digital Transformations and Use of Exponential Technologies; Deloitte: Zurich, Switzerland, 2015. Available online: http://www.industrie2025.ch/fileadmin/user_upload/ch-en-delloite-ndustry-4-0-24102014.pdf (accessed on 9 March 2017).

17. Geissbauer, R.; Vedso, J.; Schrauf, S. Industry 4.0: Building the Digital Enterprise. PwC. 2016. Available online: https://www.pwc.com/gx/en/industries/industries-4.0/landing-page/industry-4.0-buildingyour-digital-enterprise-april-2016.pdf (accessed on 9 March 2017).

18. Liu, Q.; Chen, J.; Liao, Y.; Mueller, E.; Jentsch, D.; Boerner, F.; She, M. An Application of Horizontal and Vertical Integration in Cyber-Physical Production Systems. In Proceedings of the 2015 International Conference on Cyber-Enabled Distributed Computing and Knowledge Discovery, Xi'an, China, 17-19 September 2015; pp. 110-113.

19. Ben-Daya, M.; Hassini, E.; Bahroun, Z. Internet of things and supply chain management: A literature review. Int. J. Prod. Res. 2017, 57, 4719-4742. [CrossRef]

20. Zhou, K.; Liu, T.; Zhou, L. Industry 4.0: Towards Future Industrial-Opportunities and Challenges. In Proceedings of the 12th International Conference on Fuzzy Systems and Knowledge Discovery (FSKD), Zhangiajie, China, 15-17 August 2015; pp. 2147-2152. [CrossRef]

21. Bhargava, B.; Ranchal, R.; BenOthmane, L. Secure Information Sharing in Digital Supply Chains. In Proceedings of the 3rd IEEE International Advance Computing Conference (IACC), Ghaziabad, India, 22-23 February 2013; pp. 1636-1640. [CrossRef]

22. Sun, J.; Yamamoto, H.; Matsui, M. Horizontal integration management: An optimal switching model for parallel production system with multiple periods in smart supply chain environment. Int. J. Prod. Econ. 2019. [CrossRef]

23. Zangiacomi, A.; Pessot, E.; Fornasiero, R.; Bertetti, M.; Sacco, M. Moving towards digitalization: A multiple case study in manufacturing. Prod. Plan. Control 2019, 1-15. [CrossRef]

24. Zhong, R.Y.; Newman, S.T.; Huang, G.Q.; Lan, S. Big Data for supply chain management in the service and manufacturing sectors: Challenges, opportunities, and future perspectives. Comput. Ind. Eng. 2016, 101, 572-591. [CrossRef]

25. Sklyar, A.; Kowalkowski, C.; Sörhammar, D.; Tronvoll, B. Resource integration through digitalisation: A service ecosystem perspective. J. Mark. Manag. 2019, 35, 1-18. [CrossRef]

26. Lightfoot, H.; Baines, T.; Smart, P. The servitization of manufacturing. Int. J. Oper. Prod. Manag. 2013, 33, 1408-1434. [CrossRef]

27. Kenney, M.; Zysman, J. The Rise of the Platform Economy. In Issues in Science and Technology; Springer: Berlin/Heidelberg, Germany, 2016; Volume 32.

28. Curry, E. The Big Data Value Chain: Definitions, Concepts, and Theoretical Approaches. In New Horizons for a Data-Driven Economy; Cavanillas, J., Curry, E., Wahlster, W., Eds.; Springer: Cham, Switzerland, 2016; pp. 29-37. [CrossRef]

29. MTC. From Industry 4.0 to Digitising Manufacturing-An End User Perspective. Conference Report, Manufacturing Technology Center, Coventry. 2016. Available online: http://www.the-mtc.org/pdf/Industry4-Report-2016-e.pdf (accessed on 9 March 2017).

30. Wan, J.; Cai, H.; Zhou, K. Industrie 4.0: Enabling Technologies. In Proceedings of the International Conference on Intelligent Computing and Internet of Things (IC1T), Harbin, China, 17-18 January 2015; pp. 135-140. [CrossRef]

31. Xu, L.D.; Xu, E.L.; Li, L. Industry 4.0: State of the art and future trends. Int. J. Prod. Res. 2018, 56, $2941-2962$. [CrossRef] 
32. Durugbo, C. Collaborative networks: A systematic review and multi-level framework. Int. J. Prod. Res. 2016, 54, 3749-3776. [CrossRef]

33. Appio, F.P.; Martini, A.; Massa, S.; Testa, S. Collaborative network of firms: Antecedents and state-of-the-art properties. Int. J. Prod. Res. 2017, 55, 2121-2134. [CrossRef]

34. Camarinha-Matos, L.M. Collaborative Networked Organizations: Status and Trends in Manufacturing. Annu. Rev. Control 2009, 33, 199-208. [CrossRef]

35. Camarinha-Matos, L.M.; Afsarmanesh, H.; Galeano, N.; Molina, A. Collaborative Networked Organizations-Concepts and practice in Manufacturing Enterprises. J. Comput. Ind. Eng. 2009, 57, 46-60. [CrossRef]

36. Camarinha-Matos, L.M.; Afsarmanesh, H. Roots of Collaboration: Nature-Inspired Solutions for Collaborative Networks. IEEE Access 2018, 6, 30829-30843. [CrossRef]

37. Afsarmanesh, H.; Camarinha-Matos, L.M. On the classification and management of Virtual Organisation Breeding Environments. Int. J. Inf. Technol. Manag. 2009, 8, 234-259. [CrossRef]

38. Camarinha-Matos, L.M.; Afsarmanesh, H.; Ollus, M. Methods and tools for Collaborative Networked Organizations; Springer: New York, NY, USA, 2008; ISBN 978-0-387-79423-5.

39. Camarinha-Matos, L.M.; Afsarmanesh, H. On reference models for collaborative networked organizations. Int. J. Prod. Res. 2008, 46, 2453-2469. [CrossRef]

40. Msanjila, S.; Afsarmanesh, H. Trust analysis and assessment in virtual organization breeding environments. Int. J. Prod. Res. 2008, 46, 1253-1295. [CrossRef]

41. Macedo, P.; Camarinha-Matos, L.M. Value Systems Alignment Analysis in Collaborative Networked Organizations Management. Appl. Sci. 2017, 7, 1231. [CrossRef]

42. Rosas, J.; Camarinha-Matos, L.M. An approach to assess collaboration readiness. Int. J. Prod. Res. 2009, 47, 4711-4735. [CrossRef]

43. Ferrada, F.; Camarinha-Matos, L.M. A modelling framework for collaborative network emotions. Enterp. Inf. Syst. 2019, 13, 1164-1194. [CrossRef]

44. Ermilova, E.; Afsarmanesh, H. Competency Modeling Targeted on Promotion of Organizations towards VO Involvement. In Pervasive Collaborative Networks; Springer: Boston, MA, USA, 2008; IFIP Volume 283. [CrossRef]

45. Msanjila, S.; Afsarmanesh, H. FETR: A framework to establish trust relationships among organizations in VBEs. J. Intell. Manuf. 2010, 21, 251-265. [CrossRef]

46. Afsarmanesh, H.; Camarinha-Matos, L.M.; Msanjila, S. Models, Methodologies, and Tools Supporting Establishment and Management of Second-Generation VBEs. IEEE Trans. Syst. ManCybern. Part C (Appl. Rev.) 2011, 41, 692-710. [CrossRef]

47. Oliveira, A.I.; Camarinha-Matos, L.M.; Pouly, M. Agreement negotiation support in VO creation-An illustrative case. J. Prod. Plan. Control 2010, 21, 160-180. [CrossRef]

48. Polyantchikov, I.; Shevtsenko, E.; Karaulova, T.; Kangilaski, T.; Camarinha-Matos, L.M. Virtual Enterprise Formation in the Context of a Sustainable Partner Network. Ind. Manag. Data Syst. 2017, 117, 1446-1468. [CrossRef]

49. Baldissera, T.A.; Camarinha-Matos, L.M. SCoPE: Service Composition and Personalization Environment. Appl. Sci. 2018, 8, 2297. [CrossRef]

50. Graça, P.; Camarinha-Matos, L.M. Performance Indicators for Collaborative Business Ecosystems-Literature review and trends. Technol. Forecast. Soc. Chang. 2017, 116, 237-255. [CrossRef]

51. Cancian, M.H.; Rabelo, R.; Wangenheim, C. Collaborative business processes for enhancing partnerships among software services providers. Enterp. Inf. Syst. 2015, 9, 634-659. [CrossRef]

52. Benaben, F.; Mu, W.; Boissel-Dallier, N.; Barthe-Delanoe, A.-M.; Zribi, S.; Pingaud, H. Supporting interoperability of collaborative networks through engineering of a service-based Mediation Information System (MISE 2.0). Enterp. Inf. Syst. 2015, 9, 556-582. [CrossRef]

53. Rabelo, R.J.; Noran, O.; Bernus, P. Towards the Next Generation Service Oriented Enterprise Architecture. In Proceedings of the IEEE 19th International Enterprise Distributed Object Computing Workshop, Adelaide, Australia, 21-25 September 2015. [CrossRef]

54. Schaffers, H. The Relevance of Blockchain for Collaborative Networked Organizations. In Collaborative Networks of Cognitive Systems; Springer: Cham, Switzerland, 2018; IFIP AICT Volume 534; pp. 3-17. [CrossRef] 
55. Nazarenko, A.; Camarinha-Matos, L.M. Towards Collaborative Cyber-Physical Systems. In Proceedings of the YEF-ECE 2017 - Young Engineers Forum on Electrical and Computer Engineering, Costa de Caparica, Portugal, 5 May 2017; pp. 12-17. [CrossRef]

56. Goldberg, K. Robots and the return to collaborative intelligence. Nat. Mach. Intell. 2019, 1, 2-4. [CrossRef]

57. Barata, J.; Camarinha-Matos, L.M. Coalitions of manufacturing components for shopfloor agility-The CoBASA architecture. Int. J. Netw. Virtual Organ. 2003, 2, 50-77. [CrossRef]

58. Onori, M.; Barata, J. Evolvable Production Systems: New Domains within Mechatronic Production Equipment. In Proceedings of the IEEE International Symposium on Industrial Electronics, Bari, Italy, 4-7 July 2010; pp. 2653-2657. [CrossRef]

59. Leitão, P.; Karnouskos, S.; Ribeiro, L.; Lee, J.; Strasser, T.; Colombo, A.W. Smart Agents in Industrial Cyber-Physical Systems. Proc. IEEE 2016, 104, 1086-1101. [CrossRef]

60. Adu-Kankam, K.O.; Camarinha-Matos, L.M. Towards collaborative, Virtual Power Plants: Trends and convergence. Sustain. EnergyGrids Netw. 2018, 16, 217-230. [CrossRef]

61. Camarinha-Matos, L.M.; Ferrada, F.; Oliveira, A.I. Interplay of Collaborative Networks in Product Servicing. In Collaborative Systems for Reindustrialization; Springer: Berlin/Heidelberg, Germany, 2013; PRO-VE 2013, IFIP AICT 408; pp. 51-60. [CrossRef]

62. Shen, W.; Norrie, D.H.; Barthès, J.P. Multi-Agent Systems for C, oncurrent Intelligent Design and Manufacturing; Taylor \& Francis: London, UK; New York, NY, USA, 2003.

63. Taurino, T.; Villa, A. Multi-agent Systems for Production Management in Collaborative Manufacturing. In Collaboration in a Data-Rich World; PRO-VE. IFIP AICT; Springer: Cham, Switzerland, 2017; Volume 506, pp. 175-182. [CrossRef]

64. Rabelo, R.; Camarinha-Matos, L.M.; Afsarmanesh, H. Multi-agent-based agile scheduling. J. Robot. Auton. Syst. 1999, 27, 15-28. [CrossRef]

65. Zhang, J.; Wang, X. Multi-agent-based hierarchical collaborative scheduling in re-entrant manufacturing systems. Int. J. Prod. Res. 2016, 54, 7043-7059. [CrossRef]

66. Weichhart, G.; Molina, A.; Chen, D.; Whitman, L.E.; Vernadat, F. Challenges and current developments for Sensing, Smart and Sustainable Enterprise Systems. Comput. Ind. 2016, 79, 34-46. [CrossRef]

67. Borangiu, T.; Trentesaux, D.; Thomas, A.; Leitão, P.; Barata, J. Digital transformation of manufacturing through cloud services and resource virtualization. Comput. Ind. 2019, 108, 150-162. [CrossRef]

68. Camarinha-Matos, L.M. Collaborative Networks: A Mechanism for Enterprise Agility and Resilience. In Enterprise Interoperability VI; Maertins, K., Benaben, F., Poler, R., Bourrieres, J.-P., Eds.; Springer: Cham, Switzerland, 2014; pp. 3-11. [CrossRef]

69. Romero, D.; Noran, O. Green Virtual Enterprises and their Breeding Environments: Engineering their Sustainability as Systems of Systems for the Circular Economy. IFAC-PapersOnLine 2015, 48, 2258-2265. [CrossRef]

70. Lom, M.; Pribyl, O.; Svitek, M. Industry 4.0 as a Part of Smart Cities. In Proceedings of the 2016 Smart Cities Symposium Prague (SCSP), Prague, Czech Republic, 26-27 May 2016; pp. 1-6. [CrossRef]

71. Romero, D.; Noran, O.; Afsarmanesh, H. Green Virtual Enterprise Breeding Environments Bag of Assets Management: A Contribution to the Sharing Economy. In Risks and Resilience of Collaborative Networks; IFIP AICT Series 463; Springer: Cham, Switzerland, 2015; pp. 439-447. [CrossRef]

72. Shamsuzzoha, A.; Kankaanpaa, T.; Carneiro, L.M.; Almeida, R.; Chiodi, A.; Fornasiero, R. Dynamic and collaborative business networks in the fashion industry. Int. J. Comput. Integr. Manuf. 2013, 26, 125-139. [CrossRef]

73. Almeida, R.; Carneiro, L.M.; Sá, A.; Ferreira, P.S.; Fornasiero, R. Business Communities Management. In Intelligent Non-hierarchical Manufacturing Networks; Wiley-ISTE: Hoboken, NJ, USA, 2012; ISBN 978184821481.

74. Afsarmanesh, H.; Ermilova, E. The management of ontologies in the VO breeding environments domain. Int. J. Serv. Oper. Manag. 2010, 6. [CrossRef]

75. Shadi, M.; Afsarmanesh, H. Behavioral Norms in Virtual Organizations. In Collaborative Systems for Smart Networked Environments; IFIP AICT Series 434; Springer: Heidelberg, Germany, 2014; pp. 48-59. [CrossRef]

76. Camarinha-Matos, L.M.; Oliveira, A.I.; Ferrada, F.; Sobotka, P.; Vataščinová, A.; Thamburaj, V. Collaborative Enterprise Networks for Solar Energy. In Proceedings of the 2015 International Conference on Computing and Communications Technologies (ICCCT), Chennai, India, 26-27 February 2015; pp. 93-98. [CrossRef] 
77. Camarinha-Matos, L.M.; Ferrada, F.; Oliveira, A.I.; Afsarmanesh, H. Supporting Product-Servicing Networks. In Proceedings of the 2013 International Conference on Industrial Engineering and Systems Management (IESM), Rabat, Morocco, 28-30 October 2013; pp. 1-7.

78. Mehandjiev, N.; Grefen, P. Dynamic Business Process Formation for Instant Virtual Enterprises; Springer: London, UK, 2010. [CrossRef]

79. Adamiak, K.; Malekan, H.S.; Afsarmanesh, H. Semi-automated BP Integration in Virtual Organizations. In Collaboration in a Hyperconnected World; PRO-VE 2016. IFIP AICT; Springer: Cham, Switzerland, 2016; Volume 480, pp. 87-100. [CrossRef]

80. Camarinha-Matos, L.M.; Afsarmanesh, H.; Oliveira, A.I.; Ferrada, F. Cloud-based Collaborative Business Services Provision. In Enterprise Information Systems, Lecture Notes on Business Information Processing; Springer: Cham, Switzerland, 2014; Volume 190, pp. 366-384. [CrossRef]

81. Carneiro, L.; Shamsuzzoha, A.H.M.; Almeida, R.; Azevedo, A.; Fornasiero, R.; Ferreira, P.S. Reference model for collaborative manufacturing of customised products: Applications in the fashion industry. Prod. Plan. Control 2014, 25, 1135-1155. [CrossRef]

82. Fornasiero, R.; Zangiacomi, A.; Franchini, V.; Bastos, J.; Azevedo, A.; Vinelli, A. Implementation of customisation strategies in collaborative networks through an innovative Reference Framework. Prod. Plan. Control 2016, 14, 1158-1170. [CrossRef]

83. Montoya-Torres, J.R.; Muñoz-Villamizar, A.; Vega-Mejía, C.A. On the impact of collaborative strategies for goods delivery in city logistics. Prod. Plan. Control 2016, 27, 443-455. [CrossRef]

84. Pan, S.; Ballot, E.; Huang, G.Q.; Montreuil, B. Physical Internet and interconnected logistics services: Research and applications. Int. J. Prod. Res. 2017, 55, 2603-2609. [CrossRef]

85. Ramezani, J.; Camarinha-Matos, L.M. Novel Approaches to Handle Disruptions in Business Ecosystems. In Technological Innovation for Industry and Service Systems; DoCEIS 2019. IFIP AICT; Springer: Cham, Switzerland, 2019; pp. 43-57. [CrossRef]

86. Oliveira, A.I.; Camarinha-Matos, L.M. Negotiation Support for Co-Design of Business Services. In Collaborative Systems for Smart Networked Environments; IFIP Series 434/2014; Springer: Heidelberg, Germany, 2014; pp. 98-106. [CrossRef]

87. Romero, D.; Molina, A. Collaborative networked organisations and customer communities: Value co-creation and co-innovation in the networking era. Prod. Plan. Control 2011, 22, 447-472. [CrossRef]

88. Camarinha-Matos, L.M.; Oliveira, A.I.; Ferrada, F.; Thamburaj, V. Collaborative services provision for solar power plants. Ind. Manag. Data Syst. 2017, 117, 946-966. [CrossRef]

89. Afsarmanesh, H.; Shafahi, M.; Sargolzaei, M. On Service-Enhanced Product Recommendation Guiding Users through Complex Product Specification. In Proceedings of the International Conference on Computing and Communications Technologies (ICCCT), Chennai, India, 26-27 February 2015; pp. 43-48. [CrossRef]

90. Bertoni, A.; Bertoni, M.; Panarotto, M.; Johansson, C.; Larsson, T.C. Value-driven product service systems development: Methods and industrial applications. CIRP J. Manuf. Sci. Technol. 2016, 15, 42-55. [CrossRef]

91. Boucher, X. Economic and Organizational Transition towards Product/Service Systems: The Case of French SMEs. In Collaborative Networks in the Internet of Services; IFIP AICT Series 380; Springer: Heidelberg, Germany, 2012; pp. 26-34. [CrossRef]

92. Afsarmanesh, H.; Sargolzaei, M.; Shadi, M. Semi-automated software service integration in virtual organisations. Enterp. Inf. Syst. 2015, 9, 528-555. [CrossRef]

93. Lyytinen, K.; Yoo, Y.; Boland, R.J., Jr. Digital product innovation within four classes of innovation networks. Inf. Syst. J. 2016, 26, 47-75. [CrossRef]

94. Sigala, M. Collaborative commerce in tourism: Implications for research and industry. Curr. Issues Tour. 2017, 20, 346-355. [CrossRef]

95. Janssen, R.; Blankers, I.; Moolenburgh, E.; Posthumus, B. The Impact of 3-D Printing on Supply Chain Management White Paper by TNO. 2014. Available online: http://publications.tno.nl/publication/34610218/ 0zCfLz/janssen-2014-impact.pdf (accessed on 3 April 2019).

96. Wang, A.I.; Soerensen, C.F.; Fossum, T. Mobile Peer-to-Peer Technology used to Promote Spontaneous Collaboration. In Proceedings of the International Symposium on Collaborative Technologies and Systems, St Louis, MO, USA, 20 May 2005. [CrossRef] 
97. Rossitto, C.; Bogdan, C.; Severinson-Eklundh, K. Understanding Constellations of Technologies in Use in a Collaborative Nomadic Setting. In Computer Supported Cooperative Work; Springer: Heidelberg, Germany, 2014; Volume 23, pp. 137-162. [CrossRef]

98. Moniz, A.B.; Krings, B.J. Robots Working with Humans or Humans Working with Robots? Searching for Social Dimensions in New Human-Robot Interaction in Industry. Societies 2016, 6, 23. [CrossRef]

99. Baskaran, S.; Niaki, F.A.; Tomaszewski, M.; Gill, J.S.; Chen, Y.; Jia, Y.; Mears, L.; Krovi, V. Digital Human and Robot Simulation in Automation Assembly using Siemens Process Simulate: A Feasibility Study. Procedia Manuf. 2019, 34, 986-994. [CrossRef]

100. Graessler, I.; Poehler, A. Integration of a Digital Twin as a Human Representative in a Scheduling Procedure of a Cyber-Physical Production System. In Proceedings of the 2017 IEEE International Conference on Industrial Engineering and Engineering Management, Singapore, 10-13 December 2017. [CrossRef]

101. Hafez, W. Human Digital Twin: Enabling Human-Multi Smart Machines Collaboration. In Proceedings of the SAI Intelligent Systems Conference, London, UK, 5-6 September 2019; Springer: Cham, Switzerland, 2019; Volume 1038. [CrossRef]

102. Wilson, A.J.; Daugherty, P.R. Collaborative Intelligence: Humans and AI are Joining Forces. Harvard Business Review. July-August 2018. Available online: https://www.accenture.com/t20180828T222720Z_w__ae-en/ _acnmedia/PDF-84/Accenture-Collaborative-Intelligence-2018.pdf (accessed on 29 October 2019).

103. Mezgár, I. Collaborative Networks and ICT Trends for Future CPPS and Beyond. In Collaborative Networks and Digital Transformation; PRO-VE 2019. IFIP AICT; Springer: Cham, Switzerland, 2019; Volume 568, pp. 21-28. [CrossRef]

104. Elliot, M. Stigmergic Collaboration: A Framework for Understanding and Designing Mass Collaboration. In Mass Collaboration and Education, Computer-Supported Collaborative Learning Series; Springer: Cham, Switzerland, 2016; Volume 16, pp. 65-84. [CrossRef]

105. Zamiri, M.; Camarinha-Matos, L.M. Mass Collaboration and Learning: Opportunities, Challenges, and Influential Factors. Appl. Sci. 2019, 9, 2620. [CrossRef]

106. Camarinha-Matos, L.M.; Afsarmanesh, H.; Koelmel, B. Collaborative Networks in Support of Service-Enhanced Products. In Adaptation and Value Creating Collaborative Networks; IFIP AICT Series 362/2011; Springer: Heidelberg, Germany, 2011; pp. 95-104. [CrossRef]

107. Peillon, S.; Dahmani, S.; Boucher, X. A Formal Model-Based Approach to Engineering Systems-of-Systems. In Collaborative Networks in the Internet of Services; IFIP AICT Series 380; Springer: Heidelberg, Germany, 2012; pp. 35-42. [CrossRef]

108. Song, W.; Ming, X.; Han, Y.; Xu, Z.; Wu, Z. An integrative framework for innovation management of product-service system. Int. J. Prod. Res. 2015, 53, 2252-2268. [CrossRef]

109. Durugbo, C.; Lyons, A. Collaboration for Innovation Networks: Towards a Reference Model. In Risks and Resilience of Collaborative Networks; IFIP AICT Series 463; Springer: Cham, Switzerland, 2015; pp. 311-322. [CrossRef]

110. Rabelo, R.J.; Bernus, P.; Romero, D. Innovation Ecosystems: A Collaborative Networks Perspective. In Risks and Resilience of Collaborative Networks; IFIP AICT Series 463; Springer: Cham, Switzerland, 2015; pp. 323-336. [CrossRef]

111. Rosas, J.; Macedo, P.; Tenera, A.; Abreu, A.; Urze, P. Risk Assessment in Open Innovation Networks. In Risks and Resilience of Collaborative Networks; PRO-VE 2015. IFIP AICT; Springer: Cham, Switzerland, 2015; Volume 463, pp. 27-38. [CrossRef]

112. Romero, D.; Rabelo, R.J.; Molina, A. Collaborative Networks as Modern Industrial Organisations: Real Case Studies. Int. J. Comput. Integr. Manuf. 2013, 26, 1-2. [CrossRef]

113. Fornasiero, R.; Zangiacomi, A. A structured approach for customised production in SME collaborative networks. Int. J. Prod. Res. 2013, 51, 2110-2122. [CrossRef]

114. Camarinha-Matos, L.M.; Afsarmanesh, H.; Boucher, X. The Role of Collaborative Networks in Sustainability. In Collaborative Networks for a Sustainable World; IFIP AICT Series 336/2010; Springer: Berlin/Heidelberg, Germany, 2010; pp. 1-16. [CrossRef]

115. Camarinha-Matos, L.M.; Boucher, X.; Afsarmanesh, H. Collaborative Networks for a Sustainable World; IFIP AICT Series 336; Springer: Berlin/Heidelberg, Germany, 2010.

116. Taleb, N.N. Antifragile: Things that Gain from Disorder; Random House Publishing Group: New York, NY, USA, 2012. 
117. Dahlberg, R. Resilience and Complexity: Conjoining the discourses of two contested concepts. J. Curr. Cult. Res. 2015, 7, 541-557. [CrossRef]

118. Gruzauskas, V.; Vilkas, M. Managing capabilities for supply chain resilience through it integration. Econ. Bus. 2017, 31, 30-43. [CrossRef]

119. Jones, K.H. Engineering Antifragile Systems: A Change in Design Philosophy. Procedia Comput. Sci. 2014, 32, 870-875. [CrossRef]

120. Tseitlin, A. The Antifragile Organization Embracing Failure to Improve Resilience and Maximize Availability. ACM Queue 2013, 11, 1-7.

121. Hole, K.J. Principles Ensuring Anti-fragility. In Anti-fragile ICT Systems; Simula SpringerBriefs on Computing; Springer: Cham, Switzerland, 2016; Volume 1, pp. 35-43. [CrossRef]

122. Camarinha-Matos, L.M.; Rabelo, R.; Osório, A.L. Balanced Automation. In Computer Assisted Management and Control of Manufacturing Systems; Springer: London, UK, 1997; pp. 376-414. [CrossRef]

123. Romero, D.; Noran, O.; Stahre, J.; Bernus, P.; Fast-Berglund, A. Towards a Human-Centred Reference Architecture for Next Generation Balanced Automation Systems: Human-Automation Symbiosis. In Advances in Production Management Systems: Innovative Production Management Towards Sustainable Growth; Part II, APMS 2016, AICT 460; Springer: Cham, Switzerland, 2015; pp. 556-566. [CrossRef]

124. Kowalczuk, Z.; Czubenko, M. Computational Approaches to Modelling Artificial Emotion-An Overview of the Proposed Solutions. Front. Robot. AI 2016, 3, 1-12. [CrossRef]

125. United Nations. Transforming Our World: The 2030 Agenda for Sustainable Development. UN Report A/RES/70/1. Available online: https://sustainabledevelopment.un.org/post2015/transformingourworld (accessed on 25 June 2019).

126. Deloitte. Exponential Technologies in Manufacturing Transforming the Future of Manufacturing through Technology, Talent, and the Innovation Ecosystem. 2018. Available online: https://www2.deloitte.com/content/ dam/Deloitte/us/Documents/manufacturing/us-mfg-advanced-manufacturing-technologies-report.pdf (accessed on 25 September 2019).

(C) 2019 by the authors. Licensee MDPI, Basel, Switzerland. This article is an open access article distributed under the terms and conditions of the Creative Commons Attribution (CC BY) license (http://creativecommons.org/licenses/by/4.0/). 